\title{
BNWL-210
}

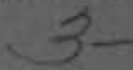

\section{UNFOLDING PARTICLE SIZE DISTRIBUTIONS}

RESEARCH

and

DEVELOPMENT

REPORT
W. L. NICHOLSON

K. R. MERCKX

MARCH 1967

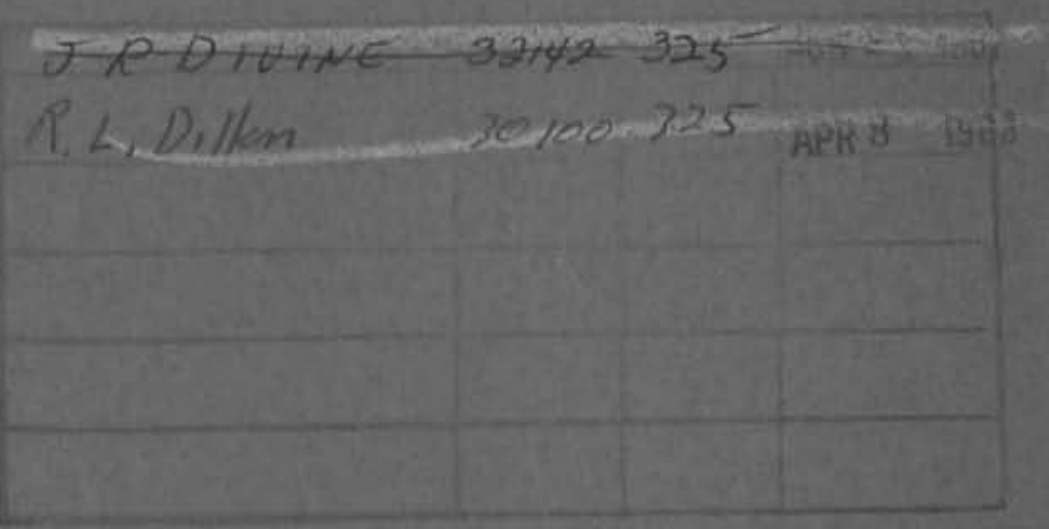

BAtTELLE $\sqrt{\text { ORTHWEST }}$

BATTELLE MEMORIAL INSTITUTE / PACIFIC NORTHWEST LABORATORY 


\section{LEGAL NOTICE}

This report was prepared as an account of Government sponsored work. Neither the United States, nor the Commission, nor any person acting on behalf of the Commiesion:

A. Makes ony warcanty or representation, expressed or implied, with respect to the occuracy, com: pleteness, or usefulness of the information contained in this report, or that the use of any information, apparatus, method, or process disclosed in this repont may not infringe privately owned rights: or

B. Assumes any liabilities with respect to the use of, of for damages resulting from the use of any information, apparatus, method, or process disclased in this report.

As used in the above, "person acting on beholf of the Commission" includes any employee or contractor of the Commission, or employee of such contractor, to the extent that such employee or contractor of the Commission, or employee of such contractor prepares, disseminotes, or provides access to, any information pursuant to his employment or contract with the Commission, or his employment with such contractior:

\section{PACIFIC NORTHWEST LABORATORY}

RICHLAND, WASHINOTON

operoted by

BATTELLE MEMORIAL INSTITUTE

for the

UNITED STATES ATOMIC ENERGY COMMISSION UNDER CONTRACT AT(45-1)-1830 


\author{
BNWL -210 \\ UC-25, Metals, \\ Ceramics, and Materials \\ UNFOLDING PARTICLE SIZE DISTRIBUTIONS \\ By \\ W. L. Nicholson \\ Mathematics Department \\ and \\ K. R. Merckx \\ Physical Metallurgy Section \\ Metallurgy Department
}

March 1967

FRET UMPESTRLTED

DISTRIBUTIGN GAAE

JUN9 '67

PACIFIC NORTHWEST LABORATORY

RICHLAND, WASHINGTON 
Printed in the United States of America Available from

Clearinghouse for Federal Scientific and Technical Information National Bureau of Standards, U. S. Department of Commerce Springfield, Virginia 22151

Price: Printed Copy $\$ 3.00 ;$ Microfiche $\$ 0.65$ 
TABLE OF CONTENTS

LIST OF FIGURES . . . . . . . . . . . . . . . . INTRODUCTION . . . . . . . . . . . . . . . 1 SUMMARY . . . . . . . . . . . . . . . 2 PARTICLE DISTRIBUTION MODEL . . . . . . . . . . . 3 DENSITY ESTIMATION . . . . . . . . . . . . . 12 RELATION TO PREVIOUS DEVELOPMENTS . . . . . . . . 15 REPLICATION PROBLEM . . . . . . . . . . . . 22 REFERENCES .................... 37 APPENDICES

I. Numerical Evaluation . . . . . . . . . . . A.1 II. Program Listing for Computer Program UNFOLD. . A.4

III. Sample Input and Output for the Program UNFOLD . . . . . . . . . . . . A.13 


\section{LIST OF FIGURES}

1 Planar Probe Sampling of a Spherical Particle. . . 17

2 Unfolded Cementite Grain Density Distribution Showing Two-Sigma Limits on Each Density Estimate ................... 20

3 Electron Photomicrograph of Replicated and Shadowed Sample... . . . . . . . . . . . 24

4 Replica From Sections Above Center of Cavity . . . 26

5 Distortions of Replicas From Sections Below Center of Cavity . . . . . . . . . . . . . . 27

6 Observed Diameters as a Function of Position of Sampling Probe... . . . . . . . . . . 28

7 Void Density Estimates and Their Two-Sigma Limits Versus Void Size for Irradiated Uranium specimens Annealed at $750{ }^{\circ} \mathrm{C}$ for Ten Minutes.

8 Void Density Distribution Based on Averaged Values for Discrete Sized Model . . . . . . . . 34 
UNFOLDING PARTICLE SIZE DISTRIBUTIONS

W. L. Nicholson and K. R. Merckx*

\section{INTRODUCTION}

Upon irradiation, uranium undergoes fission and some of the fission products are the inert gases. The collection of these inert gases into spherical cavities and the growth of these cavities produce specimens which can be studied by the methods described in this paper. The problem of estimating the distribution and range of size of these cavities was the motivating factor in this research.

A common problem in quantitative metallography is that of estimating the density of particles (number of particles per unit volume) embedded in a three-dimensional specimen. To estimate this density, a section is usually made of the specimen and the particles which intersect a given part of the section are counted. If the counted particles are grouped according to size then the data consist of a frequency-versussize histogram. A particle size distribution can be calculated from such data if the number of distinct particle sizes and the true particle shape are specified and if the particle centers are assumed to be randomly distributed within the specimen. Formulas can be developed which relate the data histogram to the true particle size distribution within the specimen. This estimation of a particle size distribution from a data histogram is often called "unfolding the distribution."

This process was first used by Scheil (13) to unfold spherical particle distributions. Schwartz $(14)$ and Saltykov

* This work was supported by the U. S. Atomic Energy Commission under contract AT(45-1)-1830. 
modified the original technique and improved the calculation procedure. The basic observation or measurement in all these developments was the diameter of the particle's intersection with a two-dimensional plane section. Johnson ${ }^{(7)}$ and Spektor (15) extended these unfolding techniques to include, respectively, the measured intersection area on a twodimensional section and intersection length on a onedimensional section. Fullman ${ }^{(5)}$ points out that the same unfolding analysis could be applied to rods and plates.

\section{SUMMARY}

This paper treats the unfolding problem in terms of a general framework which extends previous developments. The method, at least in principle, can be applied to any convex pariicle which can be sized in terms of a single characteristic dimension. A sectioning or sampling process must be usea which produces a particle intersection which, likewise, cain be sized with a single characteristic measurement. The general framework is set in terms of a probabilistic model. In addition to the density estimates, the precision of the unfolding process is estimated with a standard deviation estimate for each particle size in the distribution. Such estimates of precision have not appeared in earlier work. The general formulation also includes the possibility of imperfect observation of specimen sections. Thus, the data may be a distorted or truncated view of the set of possible particle intersections, but as long as these anomalies can be modeled mathematically the formulas still give unbiased estimates of the true specimen structure. This process can also be used to estimate distribution of sizes of voids induced by fission gases in irradiated uranium. 
The following two sections present the general particle distribution model theory and the unfolding formulas in detail. A section follows which relates our general development to the pioneer efforts of Scheil, Schwartz, Saltykov, and Johnson. An example from Saltykov (12) is treated to illustrate the importance of standard deviation estimates when the unfolded distribution is being interpreted. The last section describes the application of the general theory to an indirect microscopy analysis of a replicated plane surface. Indirect microscopy is routinely used to analyze the microstructure of irradiated uranium specimens。(2) An example is included.

Appendix $I$ is a description of the method of numerical evaluations used to write a FORTRAN IV program called UNFOLD. This program is used to unfold the frequency data collected on a Zeiss Particle Size Analyzer. Appendix II is a listing of the program. Appendix III is a sample input and output.

\section{PARTICLE DISTRIBUTION MODEL}

If an appropriate probabilistic or stochastic model is developed for a material and for the observation of samples taken from that material then a mathematical treatment can be formulated which will estimate parameters which describe the probabilistic model. The model proposed in this treatment is limited to random distributions of particles having a discrete number of particle sizes. The parameters to be estimated are the density of particles of each size. The probabilistic model describes the distribution of particles within a specimen, the intersections of particles with a sample from the specimen (sampling procedure), and the 
observation of the particle intersections (observation procedure). The development of this probabilistic model is presented in this section.

The probabilistic model is for a three-dimensional specimen of material which has distributed within it particles of various sizes but of similar geometric shape. This geometric shape must be definable in terms of a single characteristic dimension $\delta$ : for example, the diameter of a sphere, the edge of a cube, or the diameter of a circular platelet. Exactly $k$ distinct characteristic dimensions $0<\delta_{1}<\delta_{2}<\ldots<\delta_{k}$ describe the particles in the specimen. Particles of dimension $\delta_{i}(i=1,2, \ldots, k)$ are called " $i^{\text {th }}$ size." The number of $i^{\text {th }}$ size particles in the specimen is $\mu_{i} .^{*}$ The particle distribution is described with the k-dimensional particle dimension column vector $\delta=\left(\delta_{1} \delta_{2} \ldots \delta_{k}\right)^{\mathrm{T}}$ and the particle frequency vector $\underline{\mu}=\left(\mu_{1} \mu_{2} \ldots \mu_{k}\right)^{T}$. With $\tau$ the volume of the specimen, the particle density vector is

$$
\underline{e}=(1 / \tau) \underline{\mu} .
$$

* The mathematical nomenclature used in the paper attempts to distinguish the three levels of reality which characterize the unfolding problem in practice. Greek letters denote properties of the three-dimensional specimen under investigation. For example, $\mu i$ is used to denote total number of ith size particles in the specimen. Capital English letters denote true properties of the sample used to estimate specimen properties. For example, $M_{i}$ is used to denote the total number of ith size particles in the sample. Lower case English letters denote properties of the sample as they are observed. These are the data in the problem. For example, $m_{i}$ is used to denote the total number of particles in the sample which fall in the ith observational cell. vector and matrix notation is used whenever possible. The specific notation is taken from Hohn. (6) The notation for probability concepts such as random variable, distribution. mean, and variance is taken from chapter IX of Feller. (4) 
The probabilistic model specifies the particle distribution in the specimen by describing the location of particle centers or centroids. These centers are assumed to be randomly located so that the probability that any center lies in a given region of the specimen depends only on the volume of that region. Centers are independently distributed in the specimen. No allowance is made for either a clustering or a regular lattice spacing of centers. Such a distribution is called "uniform" or "homogeneous." These distributional assumptions only approximate reality. Data evaluation based on independence is adequate if the total particle volume fraction is small, say less than $10 \%$. Sampling of the specimen is done with a probe which physically pierces or cuts the specimen. The probe is characterized by a characteristic dimension A. Typical probes include one-dimensional 1 inear sections $(A=1$ ength), two-dimensional plane sections $(A=$ area), and three-dimensional thin slice sections ( $A=$ volume). A particular particle in the specimen is in the sample if and only if it is intersected by the probe. Since particle centers are uniformly distributed, sampling is random and not influenced by the orientation of the probe. Samples selected by different probes are independent if no single particle can appear in more than one sample.

The probability that a probe intersects a specific randomly located $i^{\text {th }}$ size particle is defined as $(A / \tau) F_{i}$ and must be calculable for the characteristic particle shape. In a particular application of the general theory the calculation of $F_{i}$ depends on the geometry of the particle and the character of the probe. For the case of a linear probe of length $A$ and a spherical particle of diameter $\delta_{i}$, intersection occurs if the particle center lies in a cylindrical region with the probe as its axis and its radius equal to $\delta_{i} / 2$. 
With the assumption of a random distribution of particle centers, the intersection probability is the ratio of the volume of this region to that of the specimen, or $A \pi \delta_{i}^{2} / 4 \tau$; so $\mathrm{F}_{i}=\pi \delta_{i}^{2} / 4$.

For the case of a planar probe of area $A$ and a spherical particle of diameter $\delta_{i}$, if the center of the particle is within $\delta_{i} / 2$ of either side of $A$ then an intersection will occur. Thus, the volume of the intersection region is $A \delta_{i}$ and the intersection probability is $A \delta_{i} / \tau$; so $F_{i}=\delta_{i}$.

Since the $\mu_{i} i^{\text {th }}$ size particles are randomly and independently placed with respect to the probe, the number $M_{i}$ of $i^{\text {th }}$ size particles in the sample is a random variable with a binomial distribution [Reference (4), page 135]. Thus, the probability that $M_{i}=x\left(x=0,1,2, \ldots, \mu_{i}\right)$ is given by the binomial density function for $\mu_{i}$ trials, with each trial having an intersection probability of $(A / \tau) F_{i}$. Specifically,

$$
P\left(M_{i}=x\right)=\left(\begin{array}{l}
\mu_{i} \\
x
\end{array}\right)\left[(A / \tau) F_{i}\right]^{x}\left[1-(A / \tau) F_{i}\right]^{\mu} i^{-x} \text {. }
$$

The mean and variance of the binomially distributed $\mathrm{M}_{i}$ are

$$
\begin{aligned}
E\left(M_{i}\right) & =(A / \tau) F_{i}{ }_{i} \text {, and } \\
\operatorname{Var}\left(M_{i}\right) & =(A / \tau) F_{i}\left[1-(A / \tau) F_{i}\right] \mu_{i} \text {. }
\end{aligned}
$$

Let $\underline{M}=\left(M_{1} M_{2} \ldots M_{k}\right)^{T}$ and $\underline{F}=\left(F_{1} F_{2} \ldots F_{k}\right)^{T}$ be $k$-dimensional column vector representations of particles intersected and of intersection probability per unit probe dimension per particle per unit volume. $\underline{M}$ is a random vector with mutually independent binomially distributed elements. From Equation (2) 
and the independence assumption, the mean vector and covariance matrix of $\underline{M}$ are*

$$
\begin{aligned}
E(\underline{M}) & =(A / \tau) D(\underline{F}) \underline{\mu}=D(A \underline{F}) \underline{\rho}, \text { and } \\
\operatorname{Var}(\underline{M}) & =(A / \tau) D(\underline{F})[I-(A / \tau) D(\underline{F})] D(\underline{\mu}) \\
& =D(A \underline{F})[I-(A / \tau) D(\underline{F})] D(\underline{\rho}) .
\end{aligned}
$$

If the observational process is such that all intersections can be identified as to the size of particle causing the intersection, then the particle density estimate based on infallible characterization of a single sample is the column vector $\underline{R}=\left(R_{1} R_{2} \ldots R_{k}\right)^{T}$ defined by

$$
\underline{R}=D^{-1}(\underline{A F} \underline{M}
$$

Since the matrix $D^{-1}(A F)$ is known, the mean vector and covariance matrix of $\underline{R}$ can be evaluated directly with Equation (4) and substitution of the values of $E(\underline{M})$ from Equation (3):

$$
\begin{aligned}
E(\underline{R}) & =\underline{\rho}, \text { and } \\
\operatorname{Var}(\underline{R}) & =D^{-1}(\underline{A} \underline{F})[I-(A / \tau) D(\underline{F})] D(\underline{\rho}) .
\end{aligned}
$$

Thus, $\underline{\hat{p}}=\underline{R}$ is an unbiased estimate of the true specimen density $\underline{\rho}$. The covariance matrix of $\underline{\hat{p}}=\underline{R}$ involves the unknown

\footnotetext{
* For any n-dimensional vector $x=\left(x_{1} x_{2} \ldots x_{\eta}\right)^{T}, D(x)$ is the $n$ order diagonal matrix with $x_{i}$ as the $i$ th diagonal element [Reference (6), page 296].
} 
quantity … An unbiased estimate of this covariance matrix is

$$
\hat{\operatorname{Var}}(\underline{\hat{p}})=D^{-1}(\underline{A F})[I-(A / \tau) D(\underline{F})] D(\underline{\hat{p}})
$$

Thus, the unbiased estimate $\underline{\hat{\rho}}$ and its variance estimate $\hat{\operatorname{Var}}(\underline{\hat{\rho}})$ can be determined with Equations (4) and (6) if $\underline{M}$ can be observed.

The second term in the bracket of Equation (6) cannot be calculated without knowledge of the specimen volume $\tau$. When the fraction of the specimen sampled by the probe is small (e.g., when the particles are small compared to the specimen size) $(A / \tau) D(E)$ is a minor term which can be ignored. Elimina-

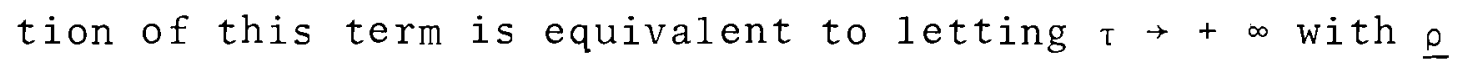
fixed; hence, the components of $M$ now become Poisson random variables [Reference (4), page 176].

This theory is applicable, for example, to observation by transmission-electron microscopy of nonoverlapping spherical particles of discrete sizes. When the sample probe is a foil thinned by etching and the particles are not etched, the volume sampled with a foil of area $A$ and thickness $t$ for a particle of diameter $\delta_{i}$ is $A\left(t+\delta_{i}\right)$. Thus the probe has a probability $A\left(t+\delta_{i}\right) / \tau$ of intersecting a spherical particle of diameter $\delta_{i}$. Hence, $F_{i}=t+\delta_{i}$. With $M$ observations of diameters $\delta$, the specimen particle density estimate $\hat{\rho}$ and its variance estimate are given by Equations (4) and (6).

The size of particle intersected by the probe cannot be recognized in many observational procedures. In planar and linear probes, only the areal and length characteristics, respectively, of the intersection can be observed. In most cases several sizes of particle could have given such an observation. The observation need not be a geometric 
measurement but could be an intensity variation given by an automated observational instrument. Any type of measurement can be treated if the observational procedure can be probabilistically modeled.

When a sampling probe intersects a particle, the observation of the intersection is described by a single characteristic dimension or signal d which is related to the particle's characteristic dimension $\delta$. At the general development level it is assumed that all possible d values lie between a lower limit $d_{o}$ and an upper limit $d_{c}$. Note that $d_{c}$ may not depend on the size of the largest particle and that $d_{0}$ need not be zero. The range $d_{0}$ to $d_{c}$ is divided into c contiguous cells. For this development to be applicable, the calculation of the probability that an $i^{\text {th }}$ size particle is measured and tallied in the $j^{\text {th }}$ of these cells must be possible. This probability is calculated conditional on a single $i^{\text {th }}$ size particle being intersected by the probe. The geometry of the particle, the character of the probe, the random distribution of particle centers, and any pecularities of the measurement process enter into this calculation.

To formalize these remarks, let $\mathrm{d}_{\mathrm{O}}<\mathrm{d}_{1}<\mathrm{d}_{2}<\ldots<\mathrm{d}_{\mathrm{c}}$ be the cell boundaries; i.e., let the $j^{\text {th }}$ cell be the interval $d_{j-1}$ to $d_{j}$. Let $P_{j i}$ be the probability that an $i^{\text {th }}$ size particle measurement $d$ satisfies $d_{j-1}<d \leqq d_{j}$, given that the particle is in the sample. Always,

$$
0 \leqq P_{j i} \leqq 1 \text { and } \sum_{j=1}^{c} P_{j i} \leqq 1 \text {. }
$$

Inequality in the summation over all c cells is allowed because a sampled particle need not be observed. For example, a positive resolution point of $\mathrm{d}_{0}$ in the measurement process for the diameter of the intersection of spherical particles 
of diameter $\delta$ with a planar probe means that a fraction $\sqrt{1-\left(d_{0} / \delta_{1}\right)^{2}}$ of the sampled particles will not be seen and hence not measured.

If $m_{j i}$ is the number of sampled $i^{\text {th }}$ size particles measured and tallied in the $j{ }^{\text {th }}$ cell and $m_{i}=\left(m_{1 i} m_{2 i} \ldots m_{c i}\right)^{T}$ is the c-dimensional column vector of frequencies for $i^{\text {th }}$ size sampled particles, then, conditional on $M_{i}$, the vector $m_{i}$ has a multinomial distribution* [Reference (3), page 157]. $\mathrm{M}_{\mathrm{i}}$ is the number of trials and $\underline{P}_{i}=\left(P_{1 i} P_{2 i} \ldots P_{c i}\right)^{T}$ is the cell probability vector. The conditional mean vector and covariance matrix of $\underline{m}_{i}$ are

$$
\begin{aligned}
E\left(\underline{m}_{i} \mid M_{i}\right) & =M_{i} \underline{P}_{i}, \text { and } \\
\operatorname{Var}\left(\underline{m}_{i} \mid M_{i}\right) & =M_{i}\left[D\left(\underline{P}_{i}\right)-\underline{P}_{i} \underline{P}_{i}^{T}\right] .
\end{aligned}
$$

Since the contributions of the various size particles to the observations falling in a given cell cannot be separated, the sum of the contributions for all sizes of particle is the observed frequency vector $\underline{m}$ where

$$
\underline{m}=\sum_{i=1}^{k} m_{i} \text {. }
$$

With the use of Equation (7) and the independence of the distributions of particles of different sizes, the conditional mean vector and covariance matrix of $\underline{m}$ are expressed in matrix notation as

* When $\sum_{j=1}^{c} P_{j i}<1, a c+1 \underline{s t}$ element $m_{c+1, i}=M_{i}-\sum_{j=1}^{c} m_{j i}$ must be included for $\underline{m}_{i}$ to have a multinomial distribution. This modification in ño way affects the following development. 


$$
\begin{aligned}
E(\underline{m} \mid \underline{M}) & =\sum_{i=1}^{k} M_{i} \underline{P}_{i}=P \underline{P M}, \text { and } \\
\operatorname{Var}(\underline{m} \mid \underline{M}) & =\sum_{i-1}^{k} M_{i}\left[D\left(\underline{P}_{i}\right)-\underline{P}_{i} \underline{P}_{i}^{T}\right]=D(P M)-P D(\underline{M}) P^{T},
\end{aligned}
$$

where $P$ is the $c$ by $k$ dimensional matrix of probabilities $P_{j i}$ with $i^{\text {th }}$ column $\underline{P}_{i}$. Application of conditional probability calculus to Equations (9) and use of Equation (3) results in the unconditional moments of the observed frequency vector being expressed in terms of an overall probability matrix $Q$ and the particle density. Specifically,

$$
\begin{aligned}
\mathrm{E}(\underline{\mathrm{m}}) & =\mathrm{E}[\mathrm{E}(\underline{\mathrm{m}} \mid \underline{\mathrm{M}})]=\mathrm{AQ} \underline{\underline{\rho}}, \text {, and } \\
\operatorname{Var}(\underline{\mathrm{m}}) & =\mathrm{E}[\operatorname{Var}(\underline{\mathrm{m}} \mid \underline{\mathrm{M}})]+\operatorname{Var}[\mathrm{E}(\underline{\mathrm{m}} \mid \underline{\mathrm{M}})] \\
& =\mathrm{AD}(\underline{\mathrm{Q}})]-\left(\mathrm{A}^{2} / \tau\right) \mathrm{QD}(\underline{\underline{\rho}}) \mathrm{Q}^{\mathrm{T}},
\end{aligned}
$$

where

$$
Q=P D(\underline{F}) \quad
$$

In Equation (10) Q is completely specified by the character of the probe and by the conditional probability of observation given that a particle is in the sample. In any application $Q$ is known and is independent of the probe dimension. The jith element in the matrix $(A / \tau) Q$ is the unconditional probability that a particular $i^{\text {th }}$ size particle, located randomly in the specimen, can be sampled by the probe and measured and tallied in the $j^{\text {th }}$ cell of the observed frequency vector. The vector $\underline{r}=(1 / \mathrm{A}) \underline{\mathrm{m}}$ is the observational density vector for the probe. Using Equation (10), the expectation of $\underline{r}$ is found to be $E(\underline{r})=Q \underline{p}$. This relationship 
between the expectation of $\underline{r}$ and $\underline{\rho}$ is the relationship of Delesse (3) between volume fraction in the specimen and area of linear fraction in the probe, given the proper choice of $Q$.

\section{DENSITY ESTIMATION}

The relationship, Equations (10), between the observed frequency vector $\underline{m}$ and the specimen density vector $\underline{\rho}$ provides the basis for estimating the specimen densities with observational data when the number of frequency distribution cells is at least as great as the number of distinct particle sizes $(\mathrm{k} \leqq \mathrm{c})$. The development presented in this section covers both the cases $k=c$ and $k<c$. The form of the estimate is different for the two cases.

If the rank of the matrix $Q$ is $k$ and $k \leqq c$, (this restriction is equivalent to the statement that no probability vector for any particle size can be expressed as a linear combination of several other such vectors) then a generalization of the Gauss-Markov Theorem [Reference (15), page 285] can be used to construct an estimate $\underline{\hat{\rho}}$ of the density vector $\underline{\hat{\rho}}$. Application of the theorem to the two cases $k=c$ and $k<c$ follows:

Case $I: k=c$.

The estimate for the particle density vector is given by

$$
\underline{\hat{\rho}}=(1 / A) Q^{-1} \underline{m} \text {. }
$$

This relationship is the solution of the system $A Q \underline{\hat{\rho}}=\underline{m}$ of $\mathrm{k}$ simultaneous linear equations in $\mathrm{k}$ unknowns. The estimate based on Equation (11) is unbiased; that is, $E(\underline{\hat{p}})=\underline{\rho}$. The variance matrix of the estimate is

$$
\operatorname{Var}(\underline{\hat{\rho}})=(1 / \mathrm{A})\left[\mathrm{Q}^{\mathrm{T}} \mathrm{D}^{-1}(\mathrm{Q} \underline{\mathrm{\rho}}) \mathrm{Q}\right]^{-1}-(1 / \tau) \mathrm{D}(\underline{\rho}) \cdot
$$


Substitution of estimates for parameters in the variance matrix and inversion of the quantity in the brackets gives the variance matrix estimate

$$
\operatorname{Var}(\underline{\hat{\rho}})=(1 / \mathrm{A}) \mathrm{Q}^{-1} \mathrm{D}(\mathrm{Q} \underline{\hat{\rho}})\left(\mathrm{Q}^{-1}\right)^{\mathrm{T}}-(1 / \mathrm{T}) \mathrm{D}(\underline{\hat{\rho}})
$$

If $v_{i j}$ is defined as the element in the $i^{\text {th }}$ row and $j^{\text {th }}$ column of $\operatorname{Var}(\underline{\hat{\rho}})$, then the standard deviation estimate for the $i^{\text {th }}$ size particle density $\hat{\rho}_{i}$ is $\sqrt{v_{i i}}$. The correlation estimate for the density pair $\left(\hat{\rho}_{i}, \hat{\rho}_{j}\right)$ is $v_{i j} / \sqrt{v_{i i} v_{j j}} \cdot$

Case I I: $\mathrm{k}<\mathrm{c}$.

Now the estimation problem is one of fitting a smooth function $A Q \underline{\hat{\rho}}$ to the observed frequency vector $\underline{m}$. A generalized least-squares method, which takes into account the unequal variances of $\underline{m}$ and the correlation among the components of $\underline{m}$, is used to make the estimate. The resulting estimate for the particle density vector is

$$
\underline{\hat{p}}=1 / \mathrm{A}\left[\mathrm{Q}^{\mathrm{T}} \mathrm{D}^{-1}(\underline{\mathrm{m}}) \mathrm{Q}\right]^{-1} \mathrm{Q}^{\mathrm{T}} \underline{\underline{1}},
$$

where 1 is a k-dimensional column vector of ones. When $k=c$ the form of Equation (14) reduces to that of Case I. Variance estimates for estimated particle density given by Equation (14) are very difficult to calculate using exact variance formulas. An approximate variance formula is given by substituting $\hat{\rho}$ into Equation (12) of Case I. If this variance formula is used, then the standard deviation and correlation estimates are calculated as for Case I.

Variance matrix formulas in the particle distribution model of the last section reflect the randomness associated with a homogeneous distribution of particle centers in the 
specimen and a particular method of "observing" the particles sampled by the probe. Commonly occuriring situations which are inadequately modeled by this approach include nonuniform distribution of particle centers and continuous distribution of particle sizes and/or shapes. An additional inadequacy may be inability to model the observational process correctly.

Since the validity of the variances of the estimates depends upon the validity of the probability model for the particle distribution and its sampling and observation, checks on the validity of the probability model should be made. When $k=c$, data from a single sampling probe are not sufficient to check model assumptions, and density estimate variance calculations must be taken on faith. If several sampling probes are used then the between-probe density estimate variability provides a check on the within-probe variance estimate based on Equation (13). Analysis of variance methods (8) can be used to determine whether the between-probe variance estimates are significantly large. Significance implies failure of model assumptions. When $k<c$, a check of model assumptions is possible with data from a single sampling probe. If the assumptions in the model are correct then the goodnessof-fit statistic,

$$
x_{c-k}^{2}=(\underline{m}-A Q \underline{\hat{p}})^{T} D^{-1}(\underline{m})(\underline{m}-A Q \underline{\hat{p}})
$$

is approximately a Chi-square random variable with $c$ - $k$ degrees of freedom [Reference (16), page 183]. Upper percentile points of the Chi-square distribution can be used for tests of significance. 


\section{RELATION TO PREVIOUS DEVELOPMENTS}

The application of the general Equations (11) and (13) to unfolding spherical particle density distributions is used to illustrate how several previous developments can be obtained with this general approach.

A spherical particle of diameter $\delta_{i}$ randomly placed in a specimen of volume $\tau$ is intersected by a planar probe or sample of area $A$ if the center of the sphere is within $\delta_{i} / 2$ of either side of the sampling plane. Thus, the effective sample volume for an intersection is $\delta_{i} A$. The probability of sample intersection per $i^{\text {th }}$ size particle is the ratio of effective sample volume to specimen volume. Thus the probability that a given $i^{\text {th }}$ size sphere is intersected is given by

$$
(A / \tau) F_{i}=A \delta_{i} / \tau \quad
$$

Equation (16) defines the sampling probability vector as $\underline{F}=\underline{\delta}$ and the characteristic sampling dimension $A$ as the area of the probing plane. The observed diameter d of the circular intersection of the particle with the sampling plane is the observational parameter. The observation falls in cell $\mathrm{j}$ when $\mathrm{d}_{j-1}<\mathrm{d} \leq \mathrm{d}_{\mathrm{j}}$. Let $\mathrm{h}$ be the distance of the sampling plane below the center of a particle with diameter $\delta_{i}\left(-\delta_{i} / 2 \leq h \leq \delta_{i} / 2\right)$. The planar probe has equal probability of intersecting the particle at any height, so the distribution for $h$ is rectangular with a probability density function

$$
p(h)=1 / \delta_{i} \text { for }-\delta_{i} / 2 \leq h \leq \delta_{i} / 2
$$


The height expressed in terms of the observed diameter d on the plane probe is

$$
h(d)= \pm(1 / 2) \sqrt{\delta_{i}^{2}-d^{2}}
$$

with the restriction that $d \leqq d_{i}$. The plus sign applies if the sampling plane is below the center and the minus if above. The situation is illustrated in Figure 1. The total probability that the observed $d$ from an intersected $i^{\text {th }}$ size particle falls in cell $j$ (i.e., $d_{j-1}<d \leq d_{j}$ ) is the sum of the probabilities for positive and negative h's. Thus,

$$
\begin{array}{rlrl}
P_{j i} & =2 \int_{\left|h\left(d_{j-1}\right)\right|}^{\left|h\left(d_{j}\right)\right|} p(h) d h & \\
& =\sqrt{1-\left(d_{j-1} / \delta_{i}\right)^{2}}-\sqrt{1-\left(d_{j} / \delta_{i}\right)^{2}} & \text { for } d_{j} \leqq \delta_{i} \\
& =\sqrt{1-\left(d_{j-1} / \delta_{i}\right)^{2}} & \text { for } d_{j-1} \leqq \delta_{i}<d_{j} ; \\
& =0 & & \text { for } \delta_{i}<d_{j-1} .
\end{array}
$$

The resulting $P$ matrix is upper triangular if the cell boundaries are selected equal to the discrete particle diameters. With this restriction $\left(d_{i}=\delta_{i}\right)$ the elements of the $Q=P D(F)$ matrix are from Equations (16) and (17)

$$
\begin{array}{rlrl}
Q_{j i} & =P_{j i} F_{i} \\
& =d_{i}\left[\sqrt{1-\left(d_{j-1} / d_{i}\right)^{2}}-\sqrt{1-\left(d_{j} / d_{i}\right)^{2}}\right] & \text { for } j \leqq i, \\
& =0 & \text { for } j>i .
\end{array}
$$




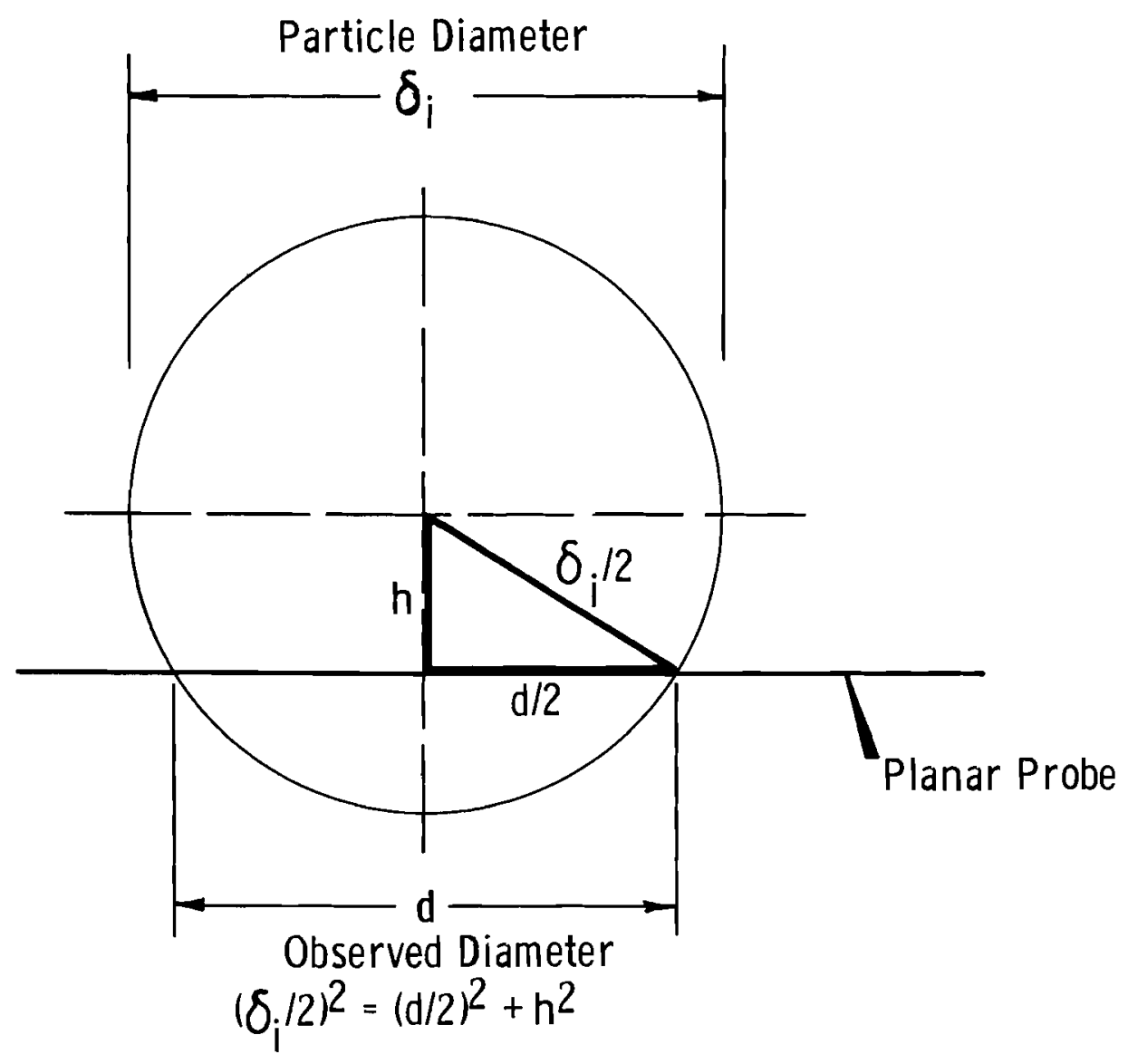

FIGURE 1. Planar Probe Sampling of a Spherical Particle

Previous "unfolding" formulas, which were based on a planar sampling device, all used Equation (18). The earliest work of Scheil(13) used $k$ cells of equal width, expressed all diameters as fractions of the maximum particle diameter, and assumed that $\mathrm{d}_{0}=0$. With $\mathrm{d}_{i}=(\mathrm{i} / \mathrm{k}) \delta_{\mathrm{k}}$ Scheil wrote Equation (18) in the form

$$
Q_{j i}=(i / k) \delta_{k}\left\{\sqrt{1-[(j-1) / i]^{2}}-\sqrt{1-(j / i)^{2}}\right\}
$$


He solved the resulting system of linear equations $A Q \hat{\rho}=\underline{m}$ by successively subtracting from lower numbered cells the frequency contribution for each particle size in turn, starting, with $\mathrm{k}^{\text {th }}$ size particles. Schwartz (14) removed the dependency on maximum particle size by calculating $Q_{j i} / \delta_{k}$. For $k=5$ and 10 he provided tables of the components of $\delta_{k} \mathrm{Q}^{-1}$. Now any particle size density could be estimated directly without back calculation from the $k^{\text {th }}$ size. Saltykov (11) introduced cell width $\Delta=\delta_{k} / k$ as the fundamental parameter in place of $\delta_{k}$. Now, $d_{i}=i \Delta$ and Equation (18) has the form

$$
Q_{j i}=\Delta\left[\sqrt{i^{2}-(j-1)^{2}}-\sqrt{i^{2}-j^{2}}\right] \text {. }
$$

Here, $Q_{i j} / \Delta$ is independent of $k$. Because of the upper triangularity of (1/A) Q the inverse for any size case gives inverses for all smaller sizes as long as the lower end of the observed distribution of diameters $d_{0}$ is an integral multiple of the common cell width $\Delta ; i . e ., d_{i}=\left(i+i_{0}\right) \Delta$. Thus, a single table replaces the size-dependent ones of Schwartz. The coefficients for any case are the elements of the principal diagonal square submatrix formed from the $i_{0}+1^{s t}, i_{0}+2^{\text {nd }}, \ldots i_{0}+k^{t h}$ rows and columns of the $Q^{-1^{\circ}}$ matrix for the maximum size case. Saltykov calculated such a table of the elements of $Q^{-1}$ for a maximum size case of $k=15$.

To illustrate the method, Saltykov's data [Reference (12), pages 293-296] on the distribution of cementite grains in spheroidized steel containing $1 \%$ carbon were unfolded. His data were taken from a photomicrograph of area $26,667 \mathrm{~mm}^{2}$ which yielded 500 grain sections with $8 \mathrm{~mm}$ as the largest section diameter. The photograph magnification was $2000 x$. Breakdown into $\mathrm{k}=8$ cells with $\mathrm{d}_{\mathrm{O}}=0$ gives the unmagnified cell boundary points as $d_{i}=(i / 2)$ microns $(i=0,1,2, \ldots, 8)$. The observed 
frequency distribution of grains in the eight cells and the results of the unfolding analysis are presented in Table $I$. The first four columns of the table reproduce Saltykov's work. Figure 2 shows the unfolded distribution given by Column 4 of the Table. The pattern of the density estimates vividly suggests a unimodal distribution with well defined tails. Once the two-sigma limits are attached it is apparent that only the peak of the distribution is established with any degree of certainty. To locate the tails precisely, approximately 50,000 sections would be needed instead of the 500 that were observed. The density estimate correlations are listed in Table II. Only the correlation for contiguous cells is appreciable. For the largest (four-micron) grains, $2 / 3$ of the observed sections should fall in cells 7 and 8 . This fraction increases as the grain size decreases. Thus, for medium (two-micron) grains, $7 / 8$ of the observed section should fall in cells 3 and 4 . More than eight cells would increase the correlations for both contiguous and noncontiguous cells. Density estimate two-sigma limits would also increase. To a first approximation these limits are proportional to the square root of the observed cell frequencies.

TABLE I. Unfolding a Cementite Grain Distribution with a Uniform-Cell-Size, Eight-Particle-Size Model

\begin{tabular}{|c|c|c|c|c|}
\hline $\begin{array}{c}\text { Cell } \\
i \\
\end{array}$ & $\begin{array}{l}\mathrm{d}_{\mathrm{i}} \\
(\mu) \\
\end{array}$ & $\mathrm{n}_{\mathrm{i}}$ & $\begin{array}{c}\hat{\rho} i \\
\left.\text { (Particles } \times 10^{-9} / \mathrm{cc}\right)\end{array}$ & $\begin{array}{c}S_{i} \\
\left.\text { (Particles } \times 10^{-9} / \mathrm{cc}\right) \\
\end{array}$ \\
\hline $\begin{array}{l}1 \\
2 \\
3 \\
4\end{array}$ & $\begin{array}{l}0.5 \\
1.0 \\
1.5 \\
2.0\end{array}$ & $\begin{array}{r}30 \\
110 \\
177 \\
104\end{array}$ & $\begin{array}{r}1.485 \\
9.331 \\
18.774 \\
9.934\end{array}$ & $\begin{array}{l}1.720 \\
1.921 \\
1.836 \\
1.182\end{array}$ \\
\hline $\begin{array}{l}5 \\
6 \\
7 \\
8\end{array}$ & $\begin{array}{l}2.5 \\
3.0 \\
3.5 \\
4.0\end{array}$ & $\begin{array}{r}39 \\
29 \\
7 \\
4\end{array}$ & $\begin{array}{l}2.793 \\
2.354 \\
0.461 \\
0.310\end{array}$ & $\begin{array}{l}0.653 \\
0.495 \\
0.228 \\
0.155\end{array}$ \\
\hline & & 500 & & \\
\hline
\end{tabular}




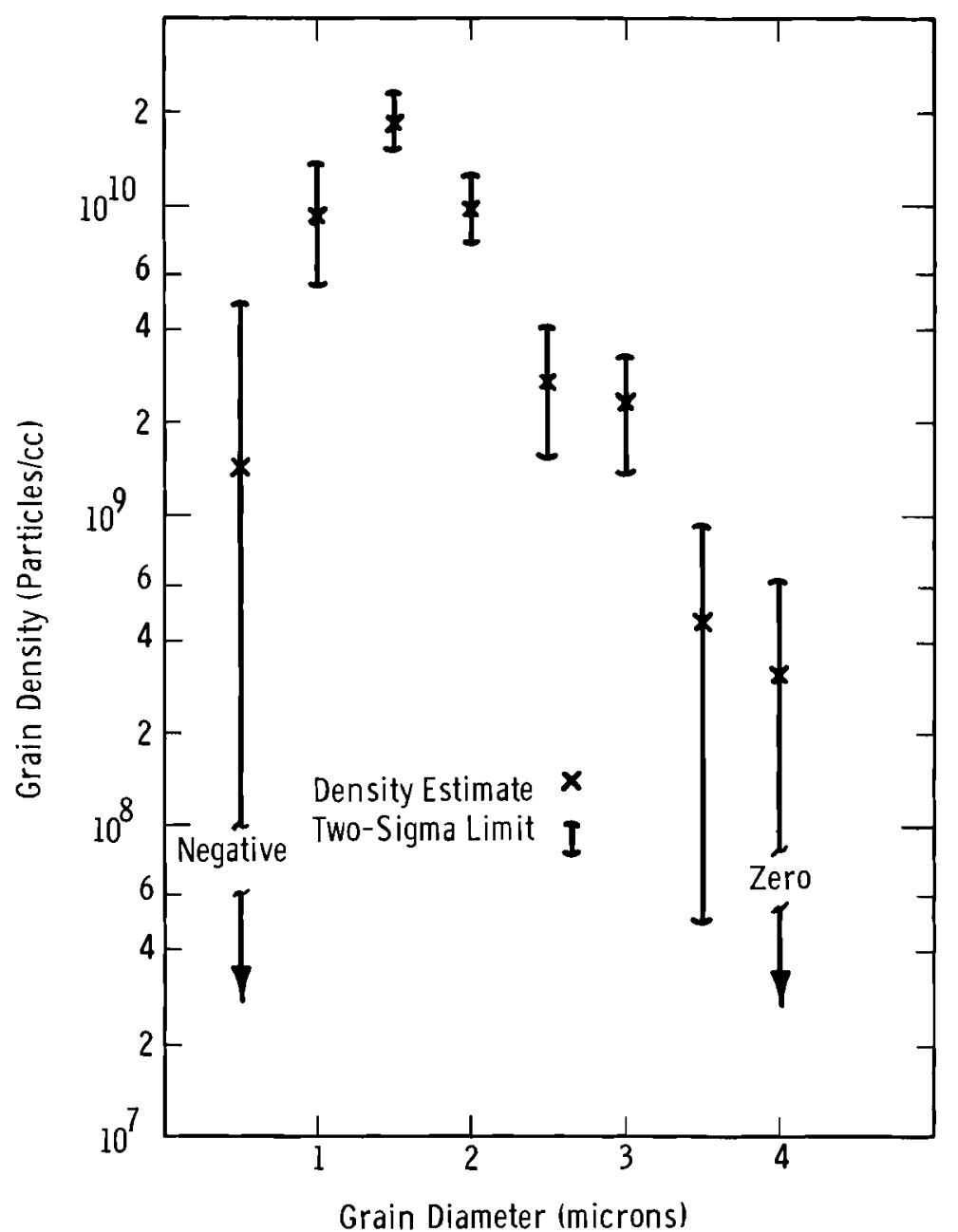

FIGURE 2. Unfolded Cementite Grain Density Distribution Showing Two-Sigma Limits on Each Density Estimate

TABLE II. Individual Particle Size Density Estimate Correlation

\begin{tabular}{|c|c|c|c|c|c|c|c|}
\hline & 2 & 3 & 4 & 5 & 6 & 7 & 8 \\
\hline 1 & -0.240 & -0.075 & -0.021 & -0.005 & -0.003 & -0.001 & -0.000 \\
\hline 2 & & -0.293 & -0.062 & -0.014 & -0.007 & -0.002 & -0.001 \\
\hline 3 & & & -0.216 & -0.035 & -0.015 & -0.003 & -0.002 \\
\hline 4 & & & & -0.175 & -0.050 & -0.100 & -0.048 \\
\hline 5 & & & & & -0.274 & -0.039 & -0.015 \\
\hline & & & & & & -0.156 & -0.042 \\
\hline & & & & & & & -0.267 \\
\hline
\end{tabular}


Johnson and Saltykov $(7,12)$ describe a method based on measuring planar intersection area a, as opposed to diameter $d$, and use exponentially increasing cell widths. Apart from the question of whether diameter or area is a better characteristic to measure, their method is identical with one based on diameters and exponentially increasing cell widths. Since a and $d$ satisfy $a=(\pi / 4) d^{2}$, an exponentially increasing cell boundary relationship of the form

$$
a_{i}=a_{0} r_{1}^{i-1} \quad\left(a_{0}>0, r_{1}>1\right)
$$

based on measuring area is equivalent to an exponentially increasing relationship

$$
d_{i}=d_{0} r^{i-1}
$$

where $\mathrm{d}_{0}=\sqrt{4 \mathrm{a}_{0} / \pi}>0$ and $r=\sqrt{r_{1}}>1$. If diameter is used fewer ith size particles fall in cell $i$, which increases correlation. If desired this can be remedied by increasing the diameter cell width factor $r$. In any event with exponentially increasing cell widths Equation (18) becomes

$$
\begin{aligned}
Q_{j i} & =d_{0} r^{i-1}\left[\sqrt{1-r^{2(j-i-1)}}-\sqrt{1-r^{2(j-i)}}\right] \\
& =d_{i} g(i-j, r) .
\end{aligned}
$$

The $Q$ matrix satisfies $Q=G D(\underline{d})$ where $G$ is upper triangular with each super diagonal in the principal direction having all components equal; i.e.,

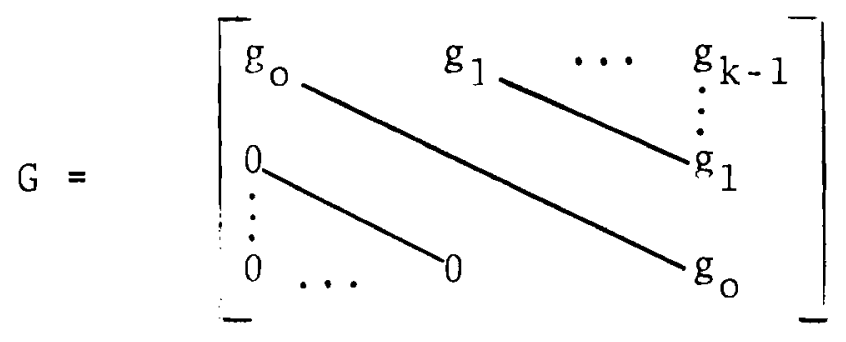


where $g_{\alpha}=g(\alpha, r)$ of Equation (19). The inverse $Q^{-1}=$ $D^{-1}(\underline{d}) G^{-1}$, where $G^{-1}$ has the same simple upper diagonal form of $\mathrm{G}$. Let $f_{\alpha}$ be the common value of elements in the $\alpha^{\text {th }}$ super diagonal of $\mathrm{G}^{-1}$. The density estimates now take the very simple form

$$
\hat{\rho}_{i}=\left(1 / d_{i} \Lambda\right) \sum_{\alpha=0}^{k-i} f_{\alpha} m_{i+\alpha} .
$$

The important thing to notice about Equation (20) is that the same vector of $f_{\alpha}$ values is used for every density estimate. These $f_{\alpha}^{\prime}$ 's are completely determined by $r$. The simplicity of Equation (20) is the key to the Johnson-Saltykov calculation method. Tables of $f_{\alpha}$ values for $\alpha=0,1,2, \ldots, 29$ and $\log _{10} r=0.1$ are given in Reference (12). This simplicity carries over to covariance calculation. Matrix manipulations in Equation (13) reduce to

$$
\left[Q^{-1} D(\underline{m})\left(Q^{-1}\right)^{T}\right]_{i j}=\sum_{\alpha=0}^{k-j} f_{j-i+\alpha} m_{j+\alpha} f_{\alpha}
$$

for $i \leqq j$.

\section{REPLICATION PROBLEM}

By forming probabilistic models for the sampling procedure and the observational procedure, a general method of estimating distributional densities was formulated. The estimation of observational data obtained from replicated surfaces of planar probes sectioning materials with distributions of spherical voids is included as an illustrative example of the general method. The physical reasoning used in selecting the model for the observational process demonstrates the flexibility of the general method and the actual application to the replication problem is one of practical significance in quantitative metallography. 
The examination of replicated surfaces with an electron microscope is an indirect observational process. Some intersections are distorted and some are not observed. This observational process ${ }^{(1)}$ begins with the sectioning of a specimen containing spherical voids, which is followed by a controlled etching of the sectioned surface. A softened plastic film is then placed on the etched surface. The film flows into the cavities formed from the intersection of the etched surface with the spherical voids. The plastic replica is hardened and removed from the etched surface of the sample. Distortion of replicated voids occurs during the replication process and breakage of the distorted replica occurs during the removal process. The replica is then shadowed with a heavy metal and coated with carbon. Not all the replicated spherical voids cast shadows; thus, further information contained in the sample is lost in the observational process. Photographs are taken of the electron transmission image of the shadowed carbon film (Figure 3). The widths of the observed shadows are measured and counted with the aid of a Zeiss Particle Size Analyzer. Matching of a variable-diameter light spot to the maximum width of the shadow is the measurement process used to estimate diameter. After this matching the Analyzer marks the observed shadows and accumulates the contribution to the correct observational cell. As used in this study, the Analyzer has 48 observational cells with exponentially increasing boundaries. These observational cell boundaries are defined by the equation

$$
\mathrm{d}_{i}=1.21125(1.0674)^{\hat{i}}[\mathrm{~mm}] \quad .
$$




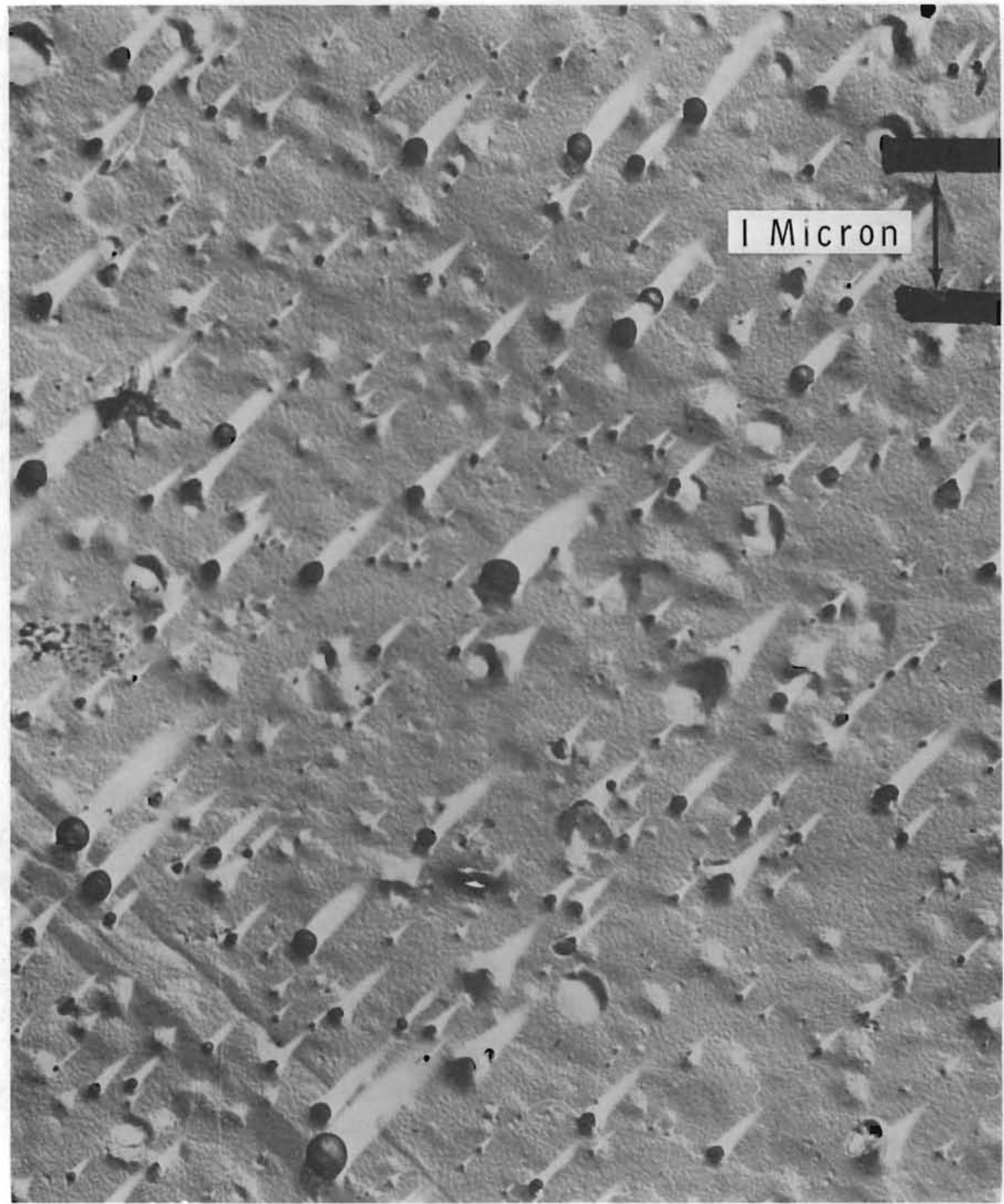

Neg $2492-E$

$\sim 15000 X$

FIGURE 3. Electron Photomicrograph of Replicated and Shadowed sample (Specimen: Irradiated uranium after a $10 \mathrm{~min}$ pulse anneal at $750{ }^{\circ} \mathrm{C}$, Sample: Replica shadowed at $15^{\circ}$ with $\mathrm{UO}_{2}$ and backed with carbon) 
Since the probe used to form the sample is a plane section, the sampling probability vector component $F_{i}$ is the same as that used in the previous section [Equation (16)], $F_{i}=\delta_{i}=d_{i}$. (This $d_{i}$ is the true diameter, not the magnified image). The probe characterization dimension $A$ is the true surface area of the portion of the replica examined in the electron microscope. The modeling of the observational procedure provides the means of accounting for replication distortions.

When the probe passes above the center of the cavity (i.e., less than half the spherical void remains to be replicated, Figure 4) the replication of the cavity by the film is assumed to be true. However, the replicas with surface tangents inclined less than the shadowing angle will not cast a shadow. For a 15 degree shadowing angle, and with the zeiss Particle Size Analyzer set for exponential cell boundaries, a maximum of twenty-one cells have nonzero probabilities. These probabilities are the same as those associated with plane sections. Because of the proportionality between cell boundaries, the probability cutoff is not dependent on the sphere size. The information lost by not observing the intersections which do not cast shadows is accounted for in the estimation procedure by the alteration of the conditional probability.

When the probe passes below the center of the cavity (i.e., more than half the spherical void remains to be replicated, Figure 5) two distortional effects must be accounted for. The first effect occurs if the section is too far below the cavity's center. In this case the replica of the cavity will break off during the stripping of the plastic replica from the sampling surface. An estimate of a breakage of one replica in three hundred was made; hence all sections with $\left(2 \mathrm{~h} / \delta_{i}\right)>0.993$ do not contribute to the observed diameters. This is equivalent to only the first eight cells having nonzero probabilities. 


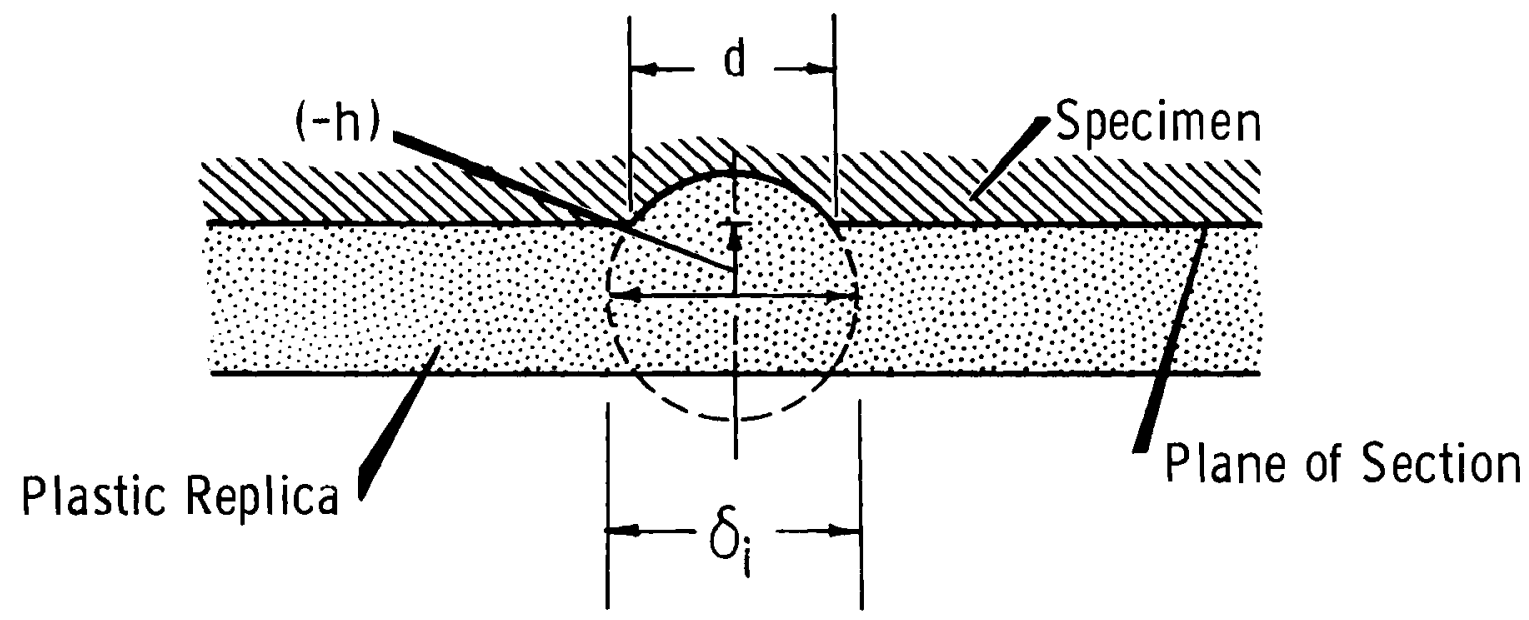

\section{Limiting Observable Diameter}

Heavy Metal Coating

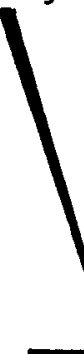

Shadow Area with no Heavy Particles
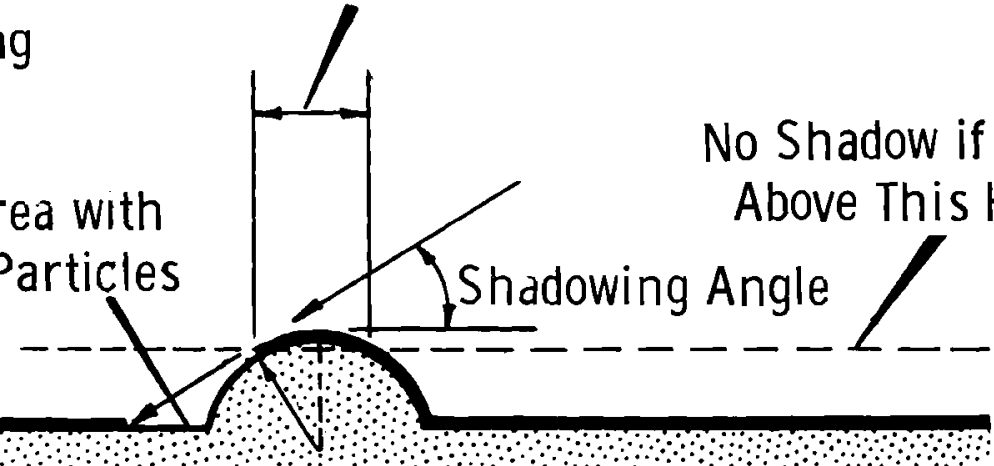

Plastic Replica

FIGURE 4. Replicas from Sections Above Center of Cavity 

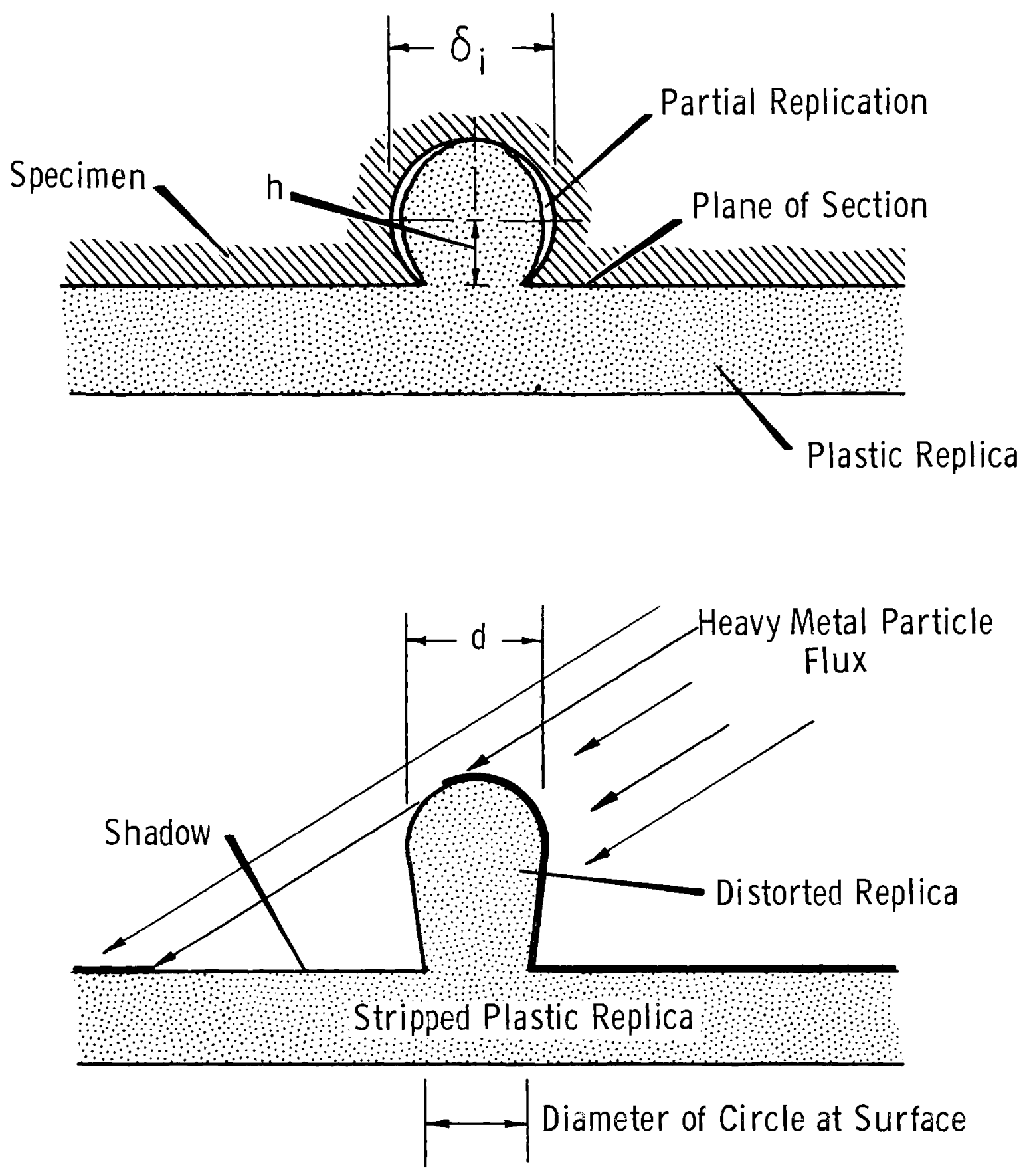

FIGURE 5. Distortions of Replicas from Sections Below Center of Cavity 
Additional observational distortion results from incomplete replication and from extrusion during stripping (Figure 5). From measurements of shadow length to width ratios and observed distortions of the shadows, the replicas of the voids greater than hemispheres are thought to be distorted into a truncated ice cream cone shape. (2) The maximum diameter of the resulting conical shape is the observed diameter. This distortional effect is estimated by assuming that the observed shadow width is related to the planar probe displacement from the cavity's center by the relation

$$
\mathrm{d} / \delta_{i}=1-0.4119\left(2 \mathrm{~h} / \delta_{i}\right)^{2}
$$

Figure 6 compares the $\left(d / \delta_{i}\right)$ ratio with that obtained from classical plane sections, both as functions of $\left(h / \delta_{i}\right)$.

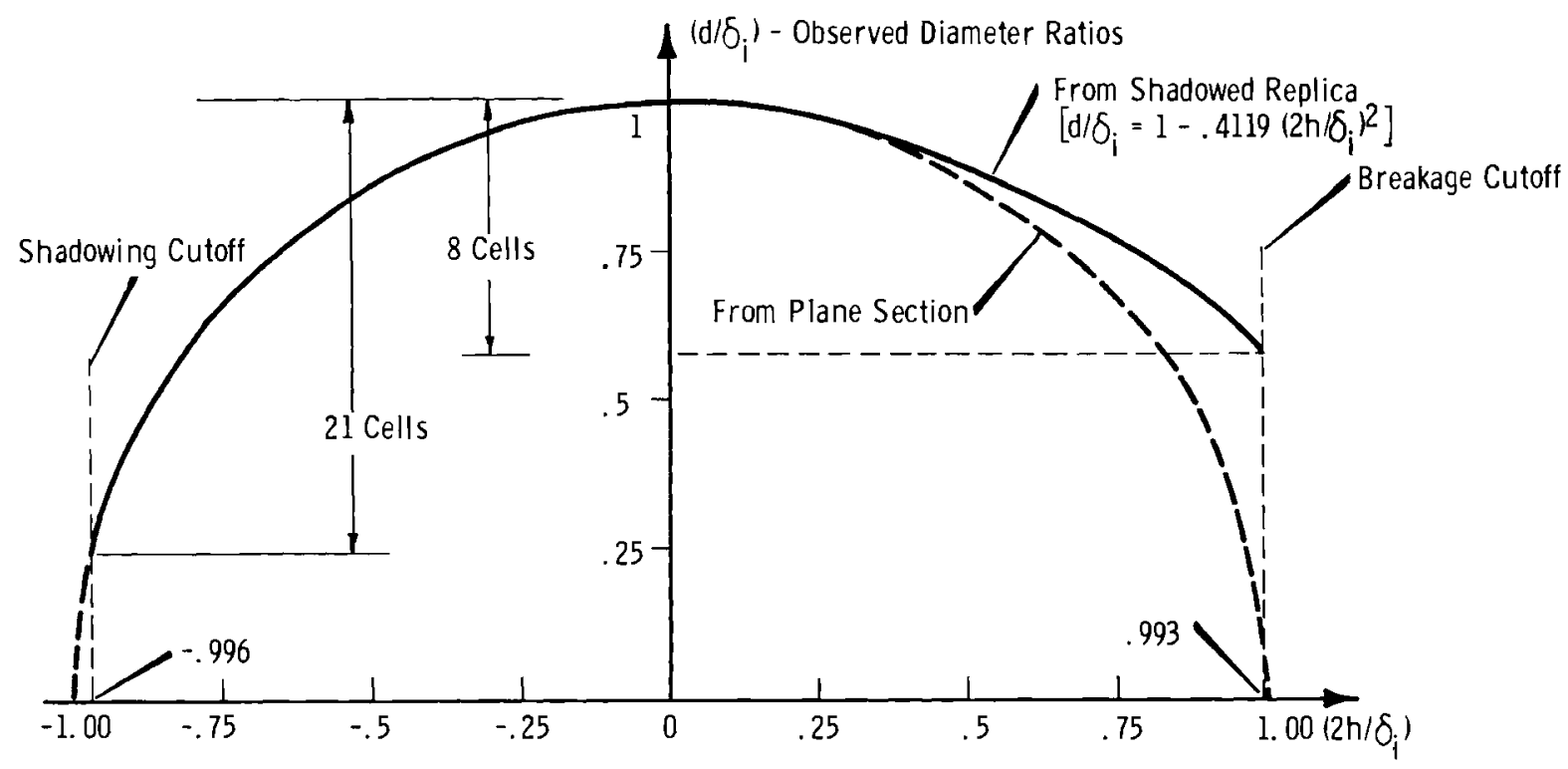

Height of Section Below Cavity Center

FIGURE 6. Observed Diameters as a Function of Position of Sampling Probe 
Since the sectioning of any void at a distance $h$ from the void center is equally probable for all h, the contribution to the probability matrix from sections above the particle's center is

$$
\left(P_{j i}\right)_{\text {above }}=(1 / 2)\left[\sqrt{1-\left(d_{j-1} / \delta_{i}\right)^{2}}-\sqrt{1-\left(d_{j} / \delta_{i}\right)^{2}}\right]
$$

for $j \leqq i \leqq j+20$; otherwise $\left(P_{j i}\right)_{\text {above }}=0$. The contribution from sections below the particle center is

$$
\left(P_{j i}\right)_{b e l o w}=\sqrt{1 / 0.8238}\left[\sqrt{1-\left(d_{j-1} / \delta_{i}\right)}-\sqrt{1-\left(d_{j} / \delta_{i}\right)}\right]
$$

for $j \leqq i \leqq j+7$; otherwise $\left(P_{j i}\right)_{\text {below }}=0$. The total cell contributions are the sum of these two probabilities. If cell

limits are equal to population diameters, $d_{i}=\delta_{i}$, the components of the $Q$ matrix, or product $P D(\underline{F})$, are

$$
\begin{aligned}
Q_{j i}= & 0.5\left[\sqrt{d_{i}^{2}-d_{j-1}^{2}}-\sqrt{d_{i}^{2}-d_{j}^{2}}\right] a_{j i} \\
& +0.77907\left[\sqrt{d_{i}\left(d_{i}-d_{j-1}\right)}-\sqrt{d_{i}\left(d_{i}-d_{j}\right)}\right] b_{j i}
\end{aligned}
$$

where $a_{j i}=1$ if $j \leqq i \leqq j+20$

$=0$ otherwise;

$$
\begin{aligned}
b_{j i} & =1 \text { if } j \leqq i \leqq j+7, \\
& =0 \text { otherwise. }
\end{aligned}
$$

The unfolding of particle distributions was adapted to real observational processes by adjusting the estimates of the conditional probabilities $P_{i j}$. The distortions and loss of sampled data which occur during the observational process required careful characterization of the observational process. (2) once 
these distortions were known, no mathematical difficulties were encountered in adjusting the unfolding procedure. This example demonstrates how experimental data are used in altering the $P$ matrix. The matrix multiplications and inversions required for any fixed procedure are readily performed by standard computer codes. The particular $Q$ matrix for the replication process as observed with a 48-cell particle analyzer has been inverted and stored for use with the program described in the Appendices. Athough the particle analyzer has fixed cell boundaries, the photographs used for evaluating the observational cell occupancies underwent different magnifications. The analysis for the $Q$ matrix was performed in terms of the coordinates of the sample and not those associated with the observational device. The conditional probability matrix $P$ is dimensionless and distributes the sampled particles into observational cells. The sampling probability vector $F$ contains the dimensional quantities and gives a linear variation with magnification. This linear variation with magnification is accounted for in the program by adjusting the $d_{i}$ of the cell boundary observed in the particle analyzer and the area of the picture to the real diameters existing in the sample.

Data obtained from replicas of irradiated and annealed uranium have been analyzed using the programs for the plane section and replicated section observational models. Table II contains a set of representative input data and the results from plane section and replicated section analyses. Slight variations in the density estimates are predicted by the two observational models. The replica section observational model consistently predicted lower variance estimates than the plane section observational mole1; thus, an improvement in the accuracy of the moleling is reflected through the reduction in variance estimates. 
TABLE III. Comparison of Density Estimates for Plane Section and Replica Section Models [Irradiated Uranium Annealed at $750^{\circ} \mathrm{C}$ for $10 \mathrm{~min}$; 15,000X; Picture Area $\left.\left(\mathrm{mm}^{2}\right)=401,088\right]$

Plane Section Mode1

Ce11 Particle Size Number (microns) Frequency ensity Estimate Standard Deviation (particles/cc) of Density Estimate

$$
\begin{array}{r}
4.0715+11 \\
4.8340+11 \\
2.1872+11 \\
6.6415+11 \\
6.4621+11 \\
8.1313+11 \\
6.6497+11 \\
3.5266+11 \\
7.2544+11 \\
6.9020+11 \\
5.4079+11 \\
5.6631+11 \\
3.2952+11 \\
1.9590+11 \\
9.5828+10 \\
2.9163+11 \\
1.5685+11 \\
9.5298+10 \\
1.0711+11 \\
9.2273+10 \\
-1.1189+10 \\
7.0639+10 \\
4.0432+10 \\
1.2270+10 \\
1.5868+10 \\
4.8902+09 \\
1.2338+10
\end{array}
$$

Replica Section Mode1

Density Estimate Standard Deviation (particles/cc) of density estimate

$4.6177+11$
$5.1503+11$
$2.3889+11$
$6.4848+11$
$6.0515+11$
$7.5506+11$
$6.1480+11$
$3.3224+11$
$6.7466+11$
$6.4130+11$
$5.0423+11$
$5.2934+11$
$3.0212+11$
$1.8340+11$
$8.5513+10$
$2.7072+11$
$1.4510+11$
$8.7034+10$
$9.9470+10$
$8.5299+10$
$-1.2350+10$
$6.6104+10$
$3.7550+10$
$1.1135+10$
$1.4767+10$
$4.8260+09$
$1.1765+10$


Graphical presentation of the unfolded data is useful in aiding interpretation. Figure 7 is the 1 ine diagram of the discrete density estimates and their two-sigma limits. This diagram is difficult to interpret in terms of a distribution of void sizes. For the majority of applications the voids or particle sizes are continuously distributed. This continuous distribution is best approximated by a fine-scale discrete distribution. However, to obtain a meaningful graphical representation for such fine-scale distributions the amount of data required is impractical. A fine-scale discrete model can be used to form a bar distribution by summing up the contributions from several particle sizes and dividing by an appropriate width. Figure 8 is such a bar distribution obtained by summing three density estimates and dividing by the total diameter range attributed to these densities. This procedure smooths the data. Variance estimates for such a bar distribution can still be obtained. Let $\hat{\zeta}_{\mathrm{r}}$ be the density estimate for the $\mathrm{r}$ th cell of the bar distribution which is of width ${ }^{N}{ }_{r}$. Then

$$
\hat{\zeta}_{r}=\left(1 / W_{r}\right) \sum_{i=1}^{3} \hat{p}_{3(r-1)+i}
$$

The variance estimate of the bar distribution estimate is

$$
\operatorname{Var}\left(\hat{\zeta}_{r}\right)=\left(1 / w_{r}\right)^{2} \sum_{i=1}^{3} \sum_{j=1}^{3} v_{3}(r-1)+i, 3(r-1)+j,
$$

where $v_{\alpha \beta}$ is the element in the $\alpha^{\text {th }}$ row and $\beta^{\text {th }}$ column of variance matrix estimate, Equation (13). The number of density estimates combined for such a representation is not restricted to the three involved in this example. 


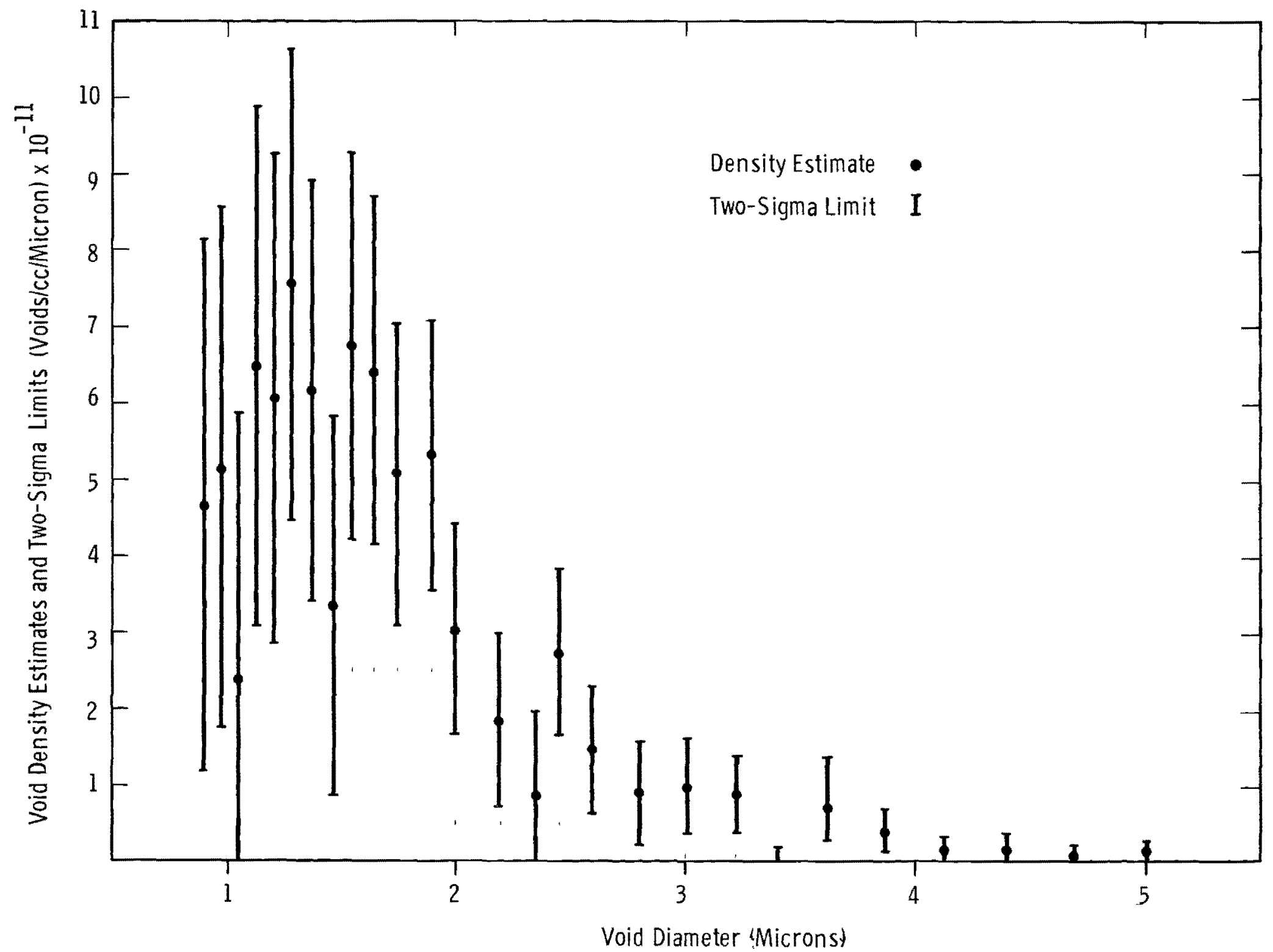

FIGURE 7. Void Density Estimates and Their Two-Sigma Variations Versus Void Size for Irradiated Uranium Specimens Annealed at $750{ }^{\circ} \mathrm{C}$ for Ten Minutes. (observational model for a replicated sample) 


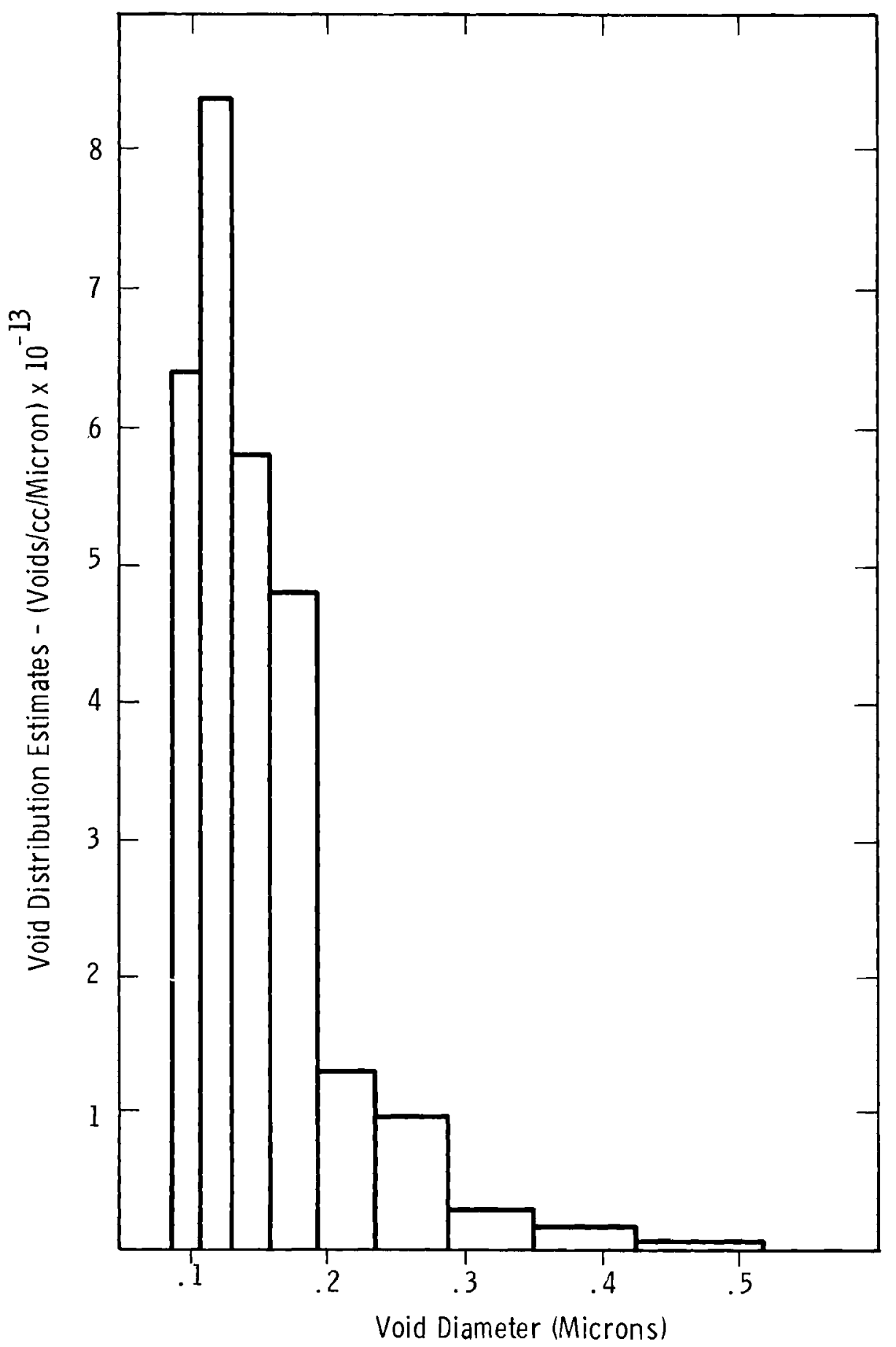

FIGURE 8. Void Density Distribution Based on Averaged Values for Discrete Sized Model. Irradiated uranium specimens annealed at $750{ }^{\circ} \mathrm{C}$ for ten minutes. (Observational model for a replicated sample) 
Since the probabilistic and statistical techniques used to form the unfolding equations were not based upon discrete sized particles, such uniform distribution estimates could have been made directly. The initial model for the particles would have been one where uniform distribution of particles exists over a size range. The $F$ vector is formed from the probabilities of intersecting one particle in each of the various size ranges, and the $P$ matrix is formed from the contributions to the observation cells conditional on a particle's being in a given size range. Ceneralizations to other distributional functions could be used to produce smoother estimates. Application of such concepts is presently under investigation. 


\section{REFERENCES}

1. T. K. Bierzein, B. Mastel, and R. D. Leggett. Possible Artifacts Associated with the Microstructure of Uranium Developed by Ion Bombardment, HW-73476, General Electric Company, Richland, Washington. Apriz 1962.

2. T. Ko Bierlein, B. Mastel, and R. D. Leggett. Metallographic Observations of Swelling in Uranium, HW-63848, General Electric Company, Richland, Washington. June 1960 .

3. A. Delesse. "Procede Mechanique pour Determiner la Composition des Roches," Annales des Mines, vol. 13. 1848 .

4. W. Felzer. An Introduction to Probability Theory and Its Applications, vol. 1, 2nd Edition, John Wiley and Sons, Inc., N.Y. 1961 .

5. R. L. Fullman. "Measurement of Particle Sizes in Opague Bodies," Trans. AIME, vol. 19. 1953.

6. E. E。Hohn. EZementary Matrix AZgebra, The Macmizian Co., N. Y. 1965 .

7. W. Johnson. "Estimation of Spatial Grain Size," Metal Progress, vol. 49, no. 1. 1946.

8. N. L. Johnson and F. C. Leone. Statistics and Experimental Design in Engineering and the Physical Sciences, vol. II, John Wiley and Sons, Ine., N. Y. 1964 .

9. C. Lanczos. Applied Analysis, Prenctice Hall, N. Y. 1956 .

10. $K . R_{n}$ Merckx. Listing of a Computer Program to Determine Particle Size Distribution, BNWL-CC-H61, Pacific Northwest Laboratory, Richland, Washington. January 1966 .

11. S. A. Saltykov. "Calculation of the Distribution Curve for the Size of Dispersed Grains," Plant Laboratory, vol. 15, no. 11, pp. 1317-1319. 1949. 
12. S. A. Saltykov. Stereometric Metallurgy, (In Russian) Moscow. 1958.

13. E. Scheil. "Statistische Gefugeuniersuchungen I," Zeitschrift fuer Metallkunda; vo. 27, no. 9, pp. 199208 . 1935

14. H. A. Schwartz. Metallographic Determination of the Size Distribution of Tempered Carbon Nodilies," Metals: and Alloys, vol. 5, no. 6, pp. 139-140. 1934.

15. A. G. Spektor. Plant Laboratory, vol. 16, no. 2. 1950 .

16. S. S. Wilks. Mathematical Statistics, John Wiley and Sons, Inc., N. Y. 1962 . 
APPENDICES 



\section{APPENDIX I}

\section{NUMERICAL EVALUATION}

The matrix formulation for unfolding or estimating particle density distributions suggests that standard computer matrix subroutines can be used for numerical evaluation. Although direct application of general matrix routines will give satisfactory numerical results, the number of numerical operations can be greatly reduced in most cases by using special properties of the unfolding formulas. Development of observational procedures and counting techniques is required for obtaining sufficient numerical data to be of statistical significance. This development was formulated so that if a standard probe or method of sampling and a standard observational method for determining cell sizes are used then the variable quantities between applications are the two scalars $\tau$ and A associated with the size of the specimen and of the sample respectively. The matrix quantity $Q$ for expressing the combined sampling and observational probability matrix for a given particle distribution model falling in observational cells does not change.

If the observed frequency vector $m$ is used to evaluate the maximum number of particle density distribution parameters, then the case of $k=c$ will be applicable and Equations (11) and (13) can be used to perform the unfolding. Besides the observational data $m$, the parameters $\tau$ and $A$, and the scale factor or magnification, only the inverse of $Q$ is needed to perform the unfolding. The inverse of $Q$ need be found only once and unfolding can be done by matrix multiplication thereafter.

For probabilistic models based on geometric observational parameters, the limits of the observational cells can usually be made to correspond to size parameter limits used to describe the particle shapes. Such typical observational cell limits 
are longest intersection for a linear probe and maximum area of intersection for a planar probe. If each cell boundary $d_{j}$ is equal to the characteristic dimension $\delta_{j}$, then the observational probability matrix $P$ will have elements with $P_{j i}=0$, for $i<j$. The resulting $Q$ matrix and $i t s$ inverse will also be upper triangular matrices. Standard methods for inverting upper triangular matrices [Reference (9), pages 130-132] can then be used to simplify the inversion of the $Q$ matrix. Since the $Q$ matrix is triangular, the estimate for the $\hat{\underline{\rho}}$ vector will not include any terms which are larger than the largest $m$ component. The same inverse of $Q$ can be used for all observational data, with the matrix summations limited to the index of the largest nonzero m component. Also the $i^{\text {th }}$ term in the matrix product in Equation (13) is for $i<j$,

$$
\left[Q^{-1} D(\underline{m}) Q^{-1}\right]_{i j}=\sum_{\alpha=j}^{k}\left[Q^{-1}\right] i \alpha m_{\alpha}\left[Q^{-1}\right] j \alpha
$$

where the upper summation limit $k$ is the index of the largest nonzero m-component. The matrix product is symmetric.

$\Lambda$ computer program called "INFOLD" ias been written for unfolding data from an observational process described by an upper triangular $Q$ matrix. The $Q^{-1}$ matrices based upon various models for the particle distributions and observational processes are stored on a tape so that the appropriate $Q^{-1}$ can be read in at the beginning of the analysis. Standard formats are used to put in the observational data, assuming a limit of 48 cells. The output of this program gives the cell dimensions, observed frequencies, estimated particle densities, and estimated standard deviations. Output of the correlation coefficients is optional. A printer controlled plot of the $\log$ of the density estimate versus cell number is also 
included as standard output. The matrix handling and input and output portions of the "UNFOLD" program are listed in Appendices II and III. Since the $Q^{-1}$ matrices are stored in a binary form, a listing of unfolding matrices presently available on tape is not included.

Another program, "SALTY," handles the planar section analysis where the $Q$ and $Q^{-1}$ matrices are created for prescribed particle sizes and cell boundaries. A listing of this program has been published ${ }^{(10)}$ which includes subroutine "TRIVRT" for inverting triangular matrices. 


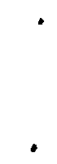


APPENDIX II

PROGRAM LISTING FOR COMPUTER PROGRAM UNFOLD

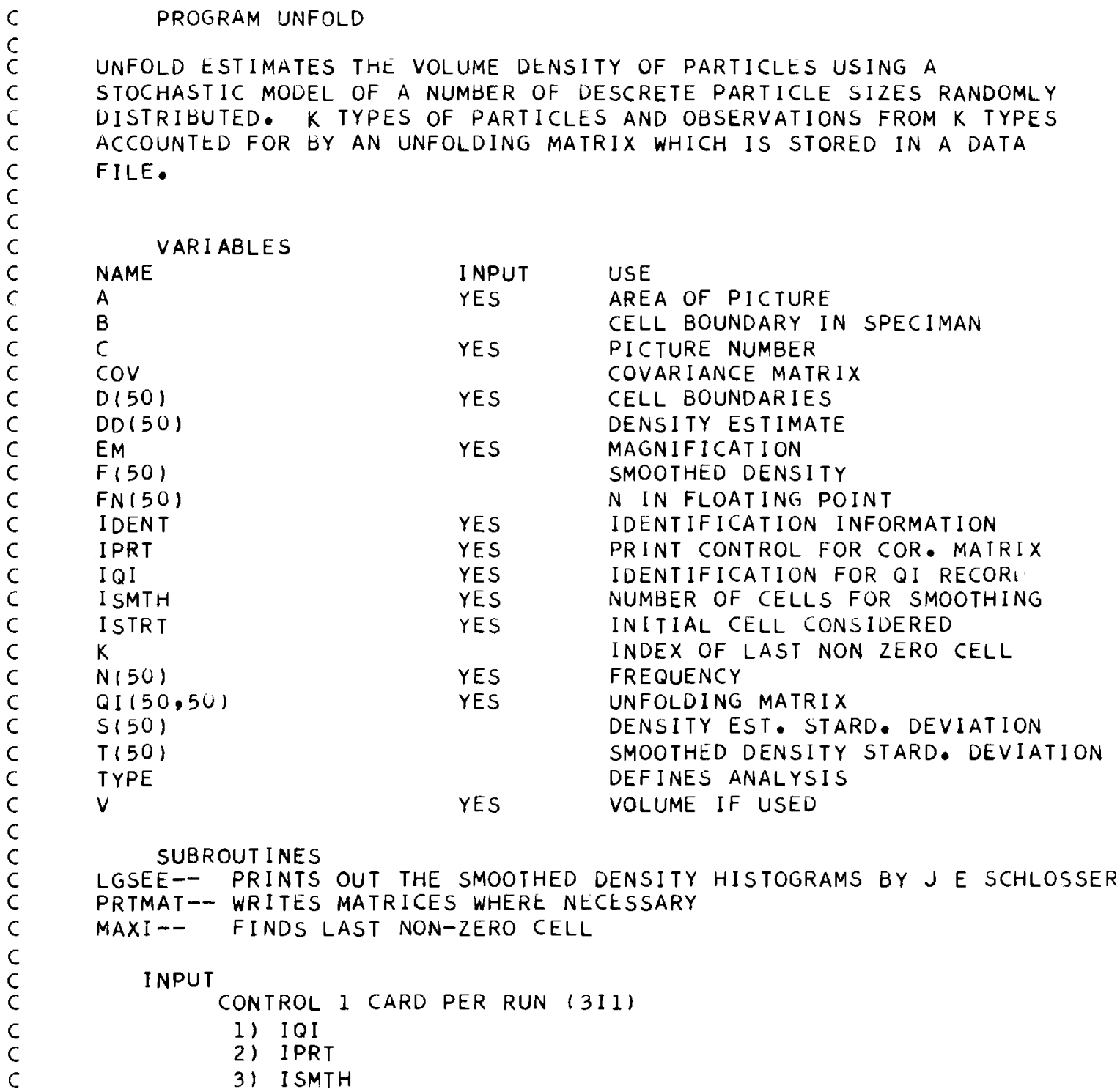


FROM TAPE

1) $D$

2) QI--THESE UO NOT INCLUDE EM HENGE PROGRAM CORRECTS

PARAMETERS 2 CARUS PER CASE $(12 A 6),\left(1 X_{0} F 5,0,1 X, 12,1 X, 3 F 10.0\right)$ CARD 1

1) IDENT

CARD 2

1) C - PICTURE NUMBER

2) ISTRT - INITIAL CELL

3) EM - MAGNIFICATION

4) A - AREA OF SECTION

5) $V$ - VOLUME OF SPLCIMAN

DATA 3 CARDS PER CASE $(8 x, 1614)$

1) $N(K)$ FREQUENCIES

0090

OUTPUT

REPORT HEAUING TYPE OF SAMPLING AND OBSERVATIONAL PROCEDURE ANO SAMPLE IUENTIFICATION

SUBHEADING INFORMATION

1) PICTURE NUMBER

2) MAGNIFICATION

3) AREA

4) VOLUME

SUBHEADING - LAOELS

1) CELL NO.

2) PARTICLE SIZE (MICRONS)

3) OBSERVEU FREQUENCY

4) DENSITY ESTIMATE (PART I CLES/CC.)

5) STANDARU UEVIATIUN OF DENSITY ESTIMATE

6) SMOOTHEU UENSITY (PARTICLES/CC./MICRON)

7) STANDARD DEVIATIUN OF SMOOTHEU DENSITY

DENSITY ESTIMATE CORRELATION MATRIX

LOG PLOT-SMOOTHED DENSITY HISTOGRAM

0120

0150

0160

0170

0180

0210

0220

0230

0240

0250

0260

0270

0280

0290

0300

0310

0320

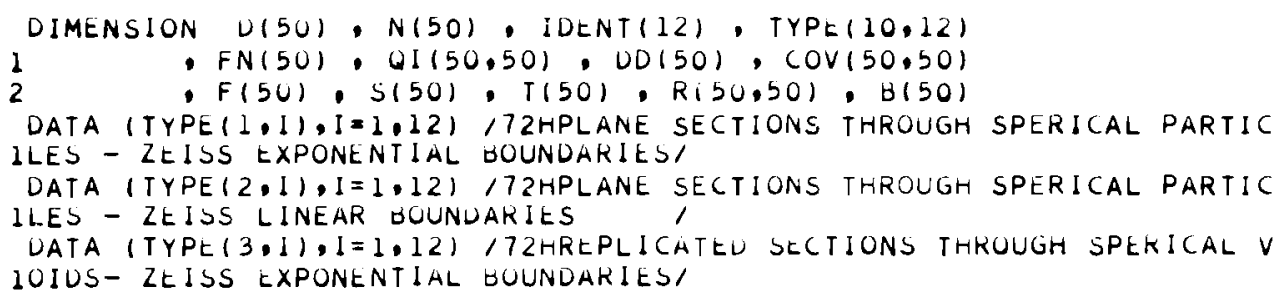




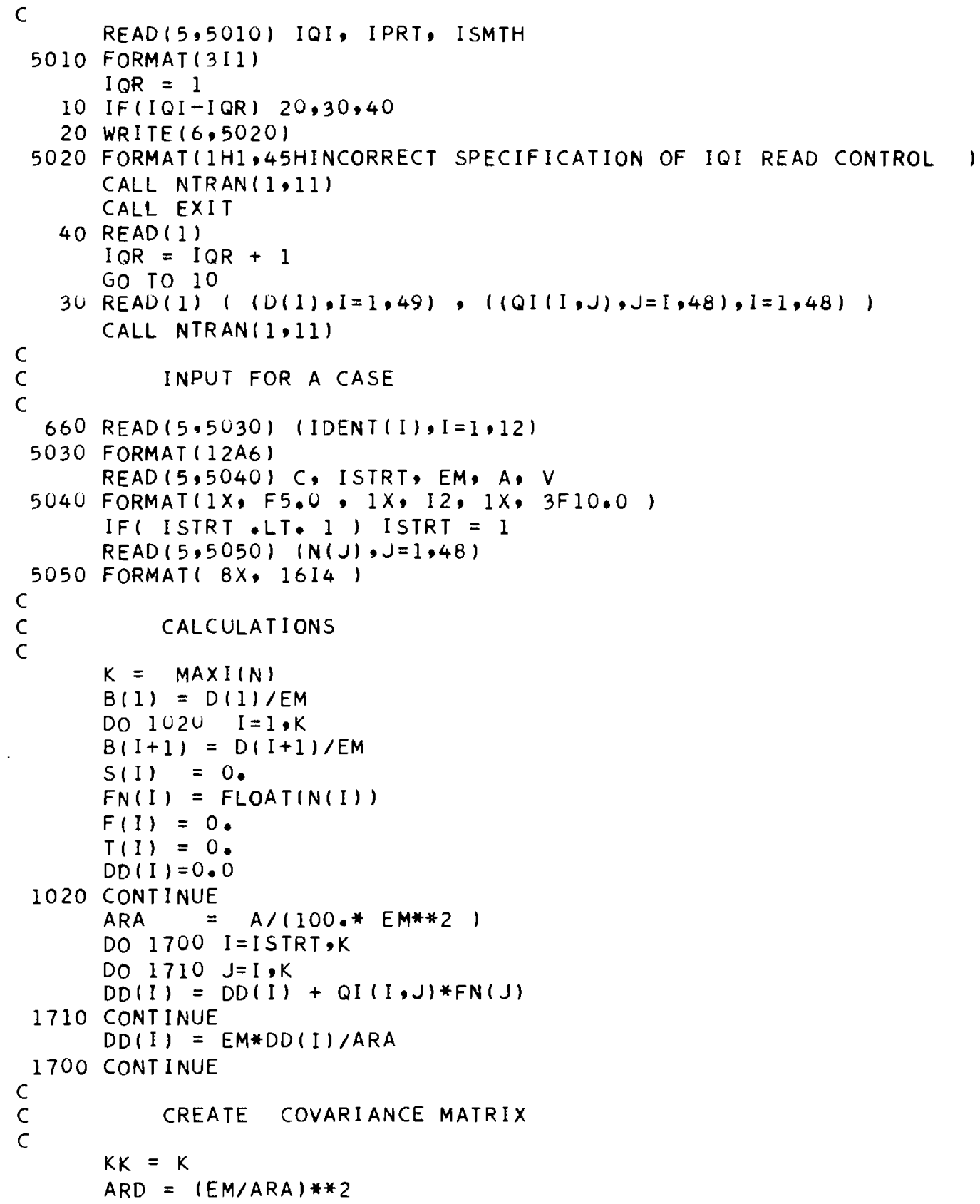




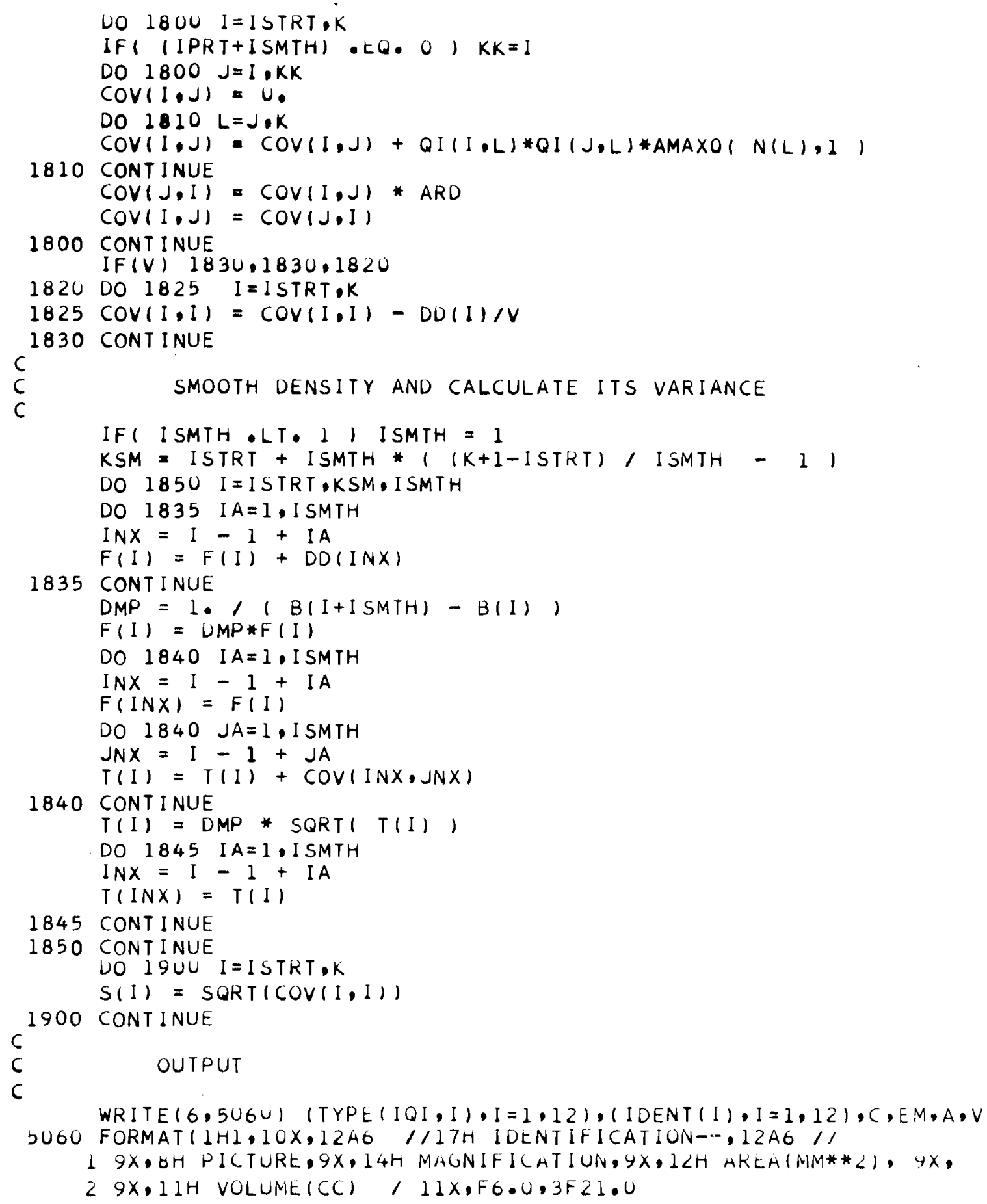




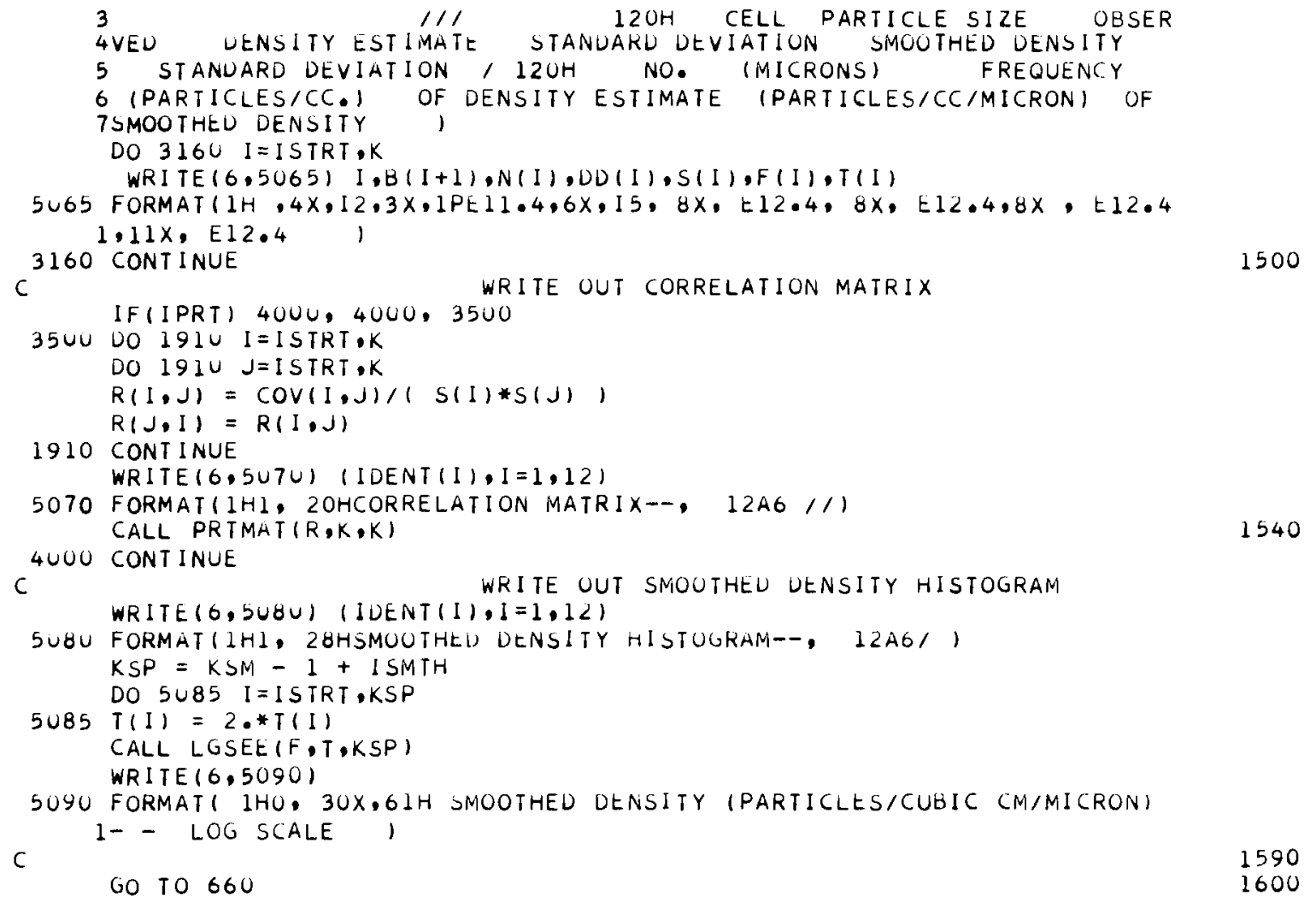


LISTING OF SUBROUTINES

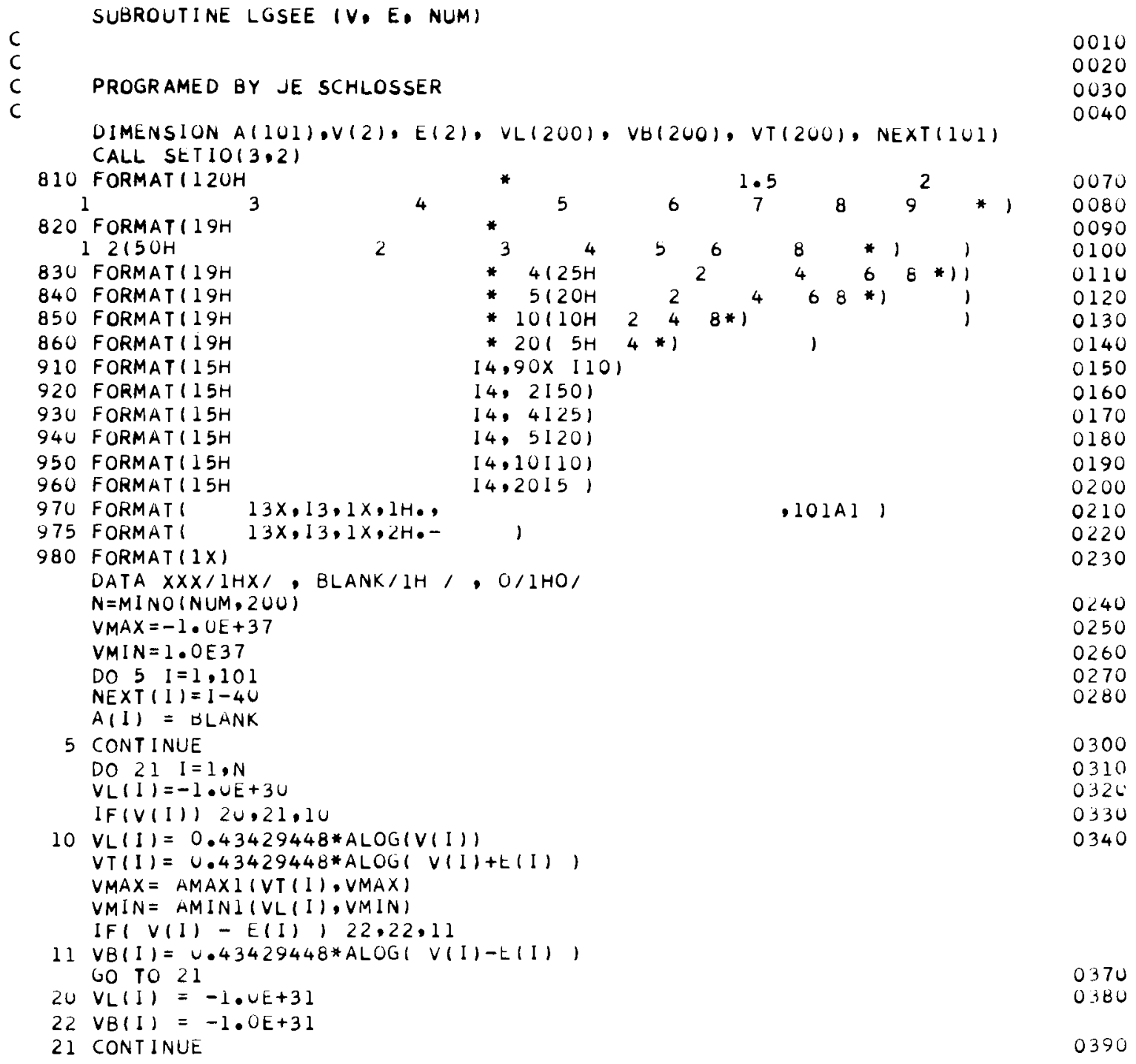




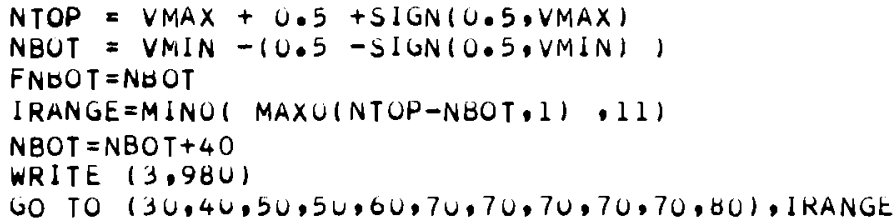

100 CONTINUE

0400

0410

0420

0430

0440

0450

0460

0470

0480

0490

0500

0510

0520

0530

0540

0550

0560

0570

0580

0590

0600

0610

0620

0630

0640

0050

0660

0670

0680

0690

0700

0710

0720

0730

0740

0750

0760

0770

0780

0790

0800

0810

0820

0830

0840

0850

0860

0870

0880 


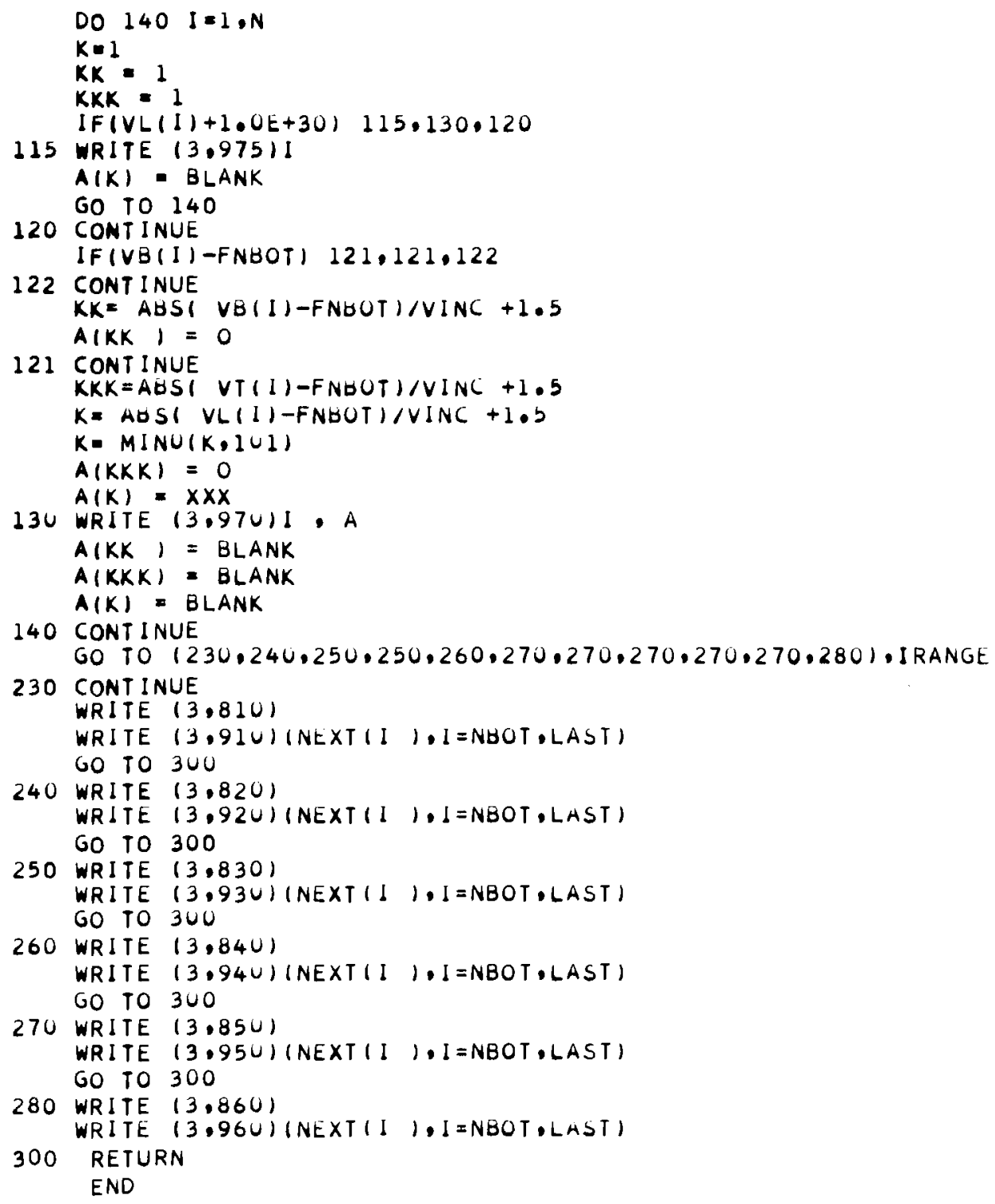

0990 


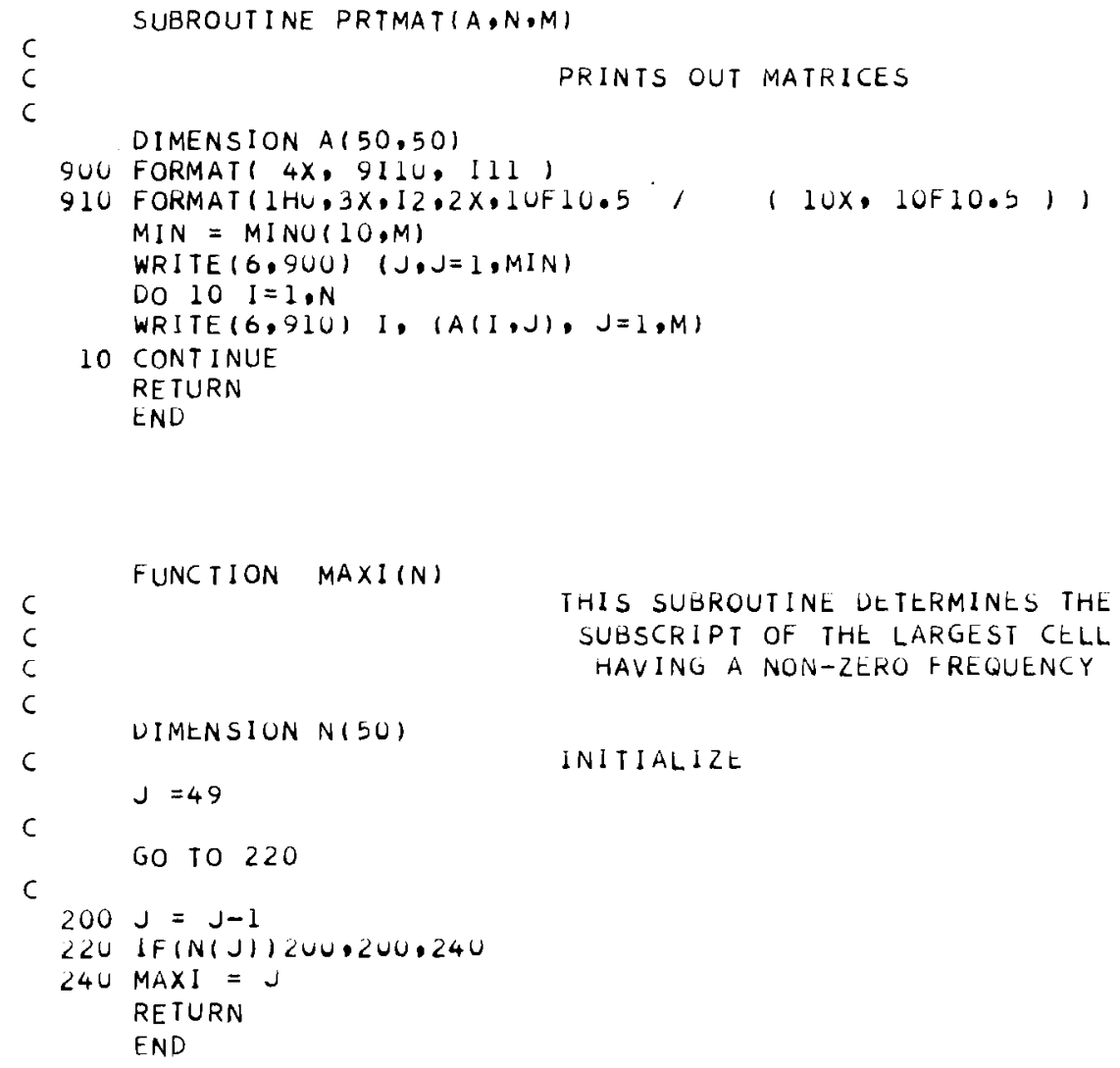

910 FORMAT(IHU, 3X, I2.2X,1UF10.5, (1UX, 1OF10.5),

INITIALIZE

THIS SUBROUTINE UETERMINES THE SUBSCRIPT OF THE LARGEST CELL HAVING A NON-ZERO FREQUENCY

PRINTS OUT MATRICES

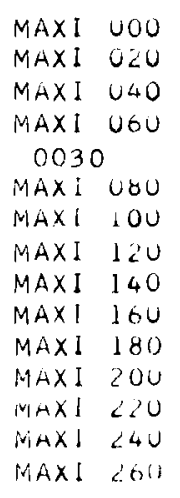


APPENDIX III

SAMPLE INPUT AND OUTPUT FOR THE PROGRAM UNFOLD

SAMPLE INPUT

313

2488

․․․

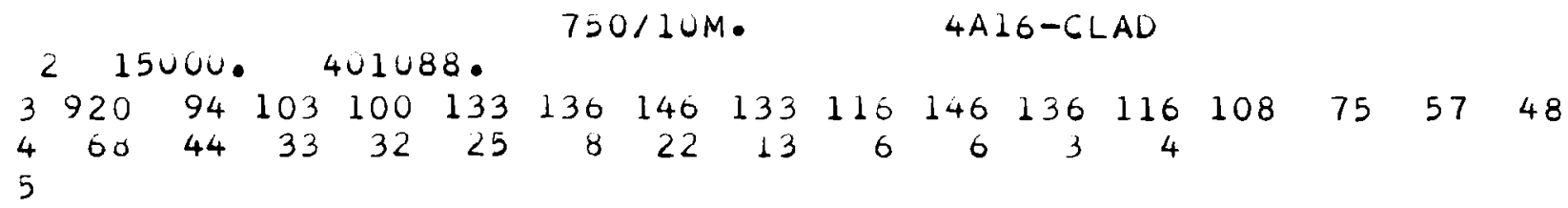

SAMPLE OUTPUT

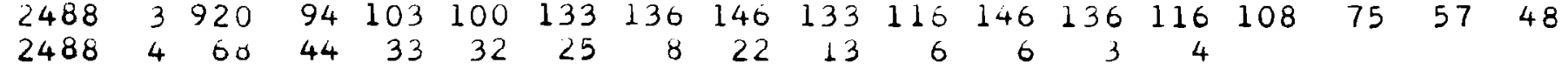

2488 


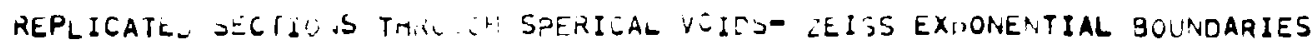

ILE..TIFICATIO/NO- $24: 8$

ICTURE

24880 .
PARTICLE SD E (MICRONS) $9.2036-0 z$

$9.8236-4 c$

1. $4885-i j$

$1.1192-41$

$1.1946-=1$

$1.2751-i$

$1.4527-0$

$1.4527-505-01$

$1.6550-01$

$1.6550-v i$
$1.7065-i$

$1.7665-i$

$1.8855-u$

2.0126-i

2.1481-u:

2.2929-6.

2.6122-u1

2.7882-01

2.9761-01

3.1766-u1

3.3906-01

$3 \cdot 6+90=01$

$3.8628-01$

$4.8631-01$

$4.4009-01$

$4.6974-6$.

$4.6974-6$.
$5.0135=6$
$750 / 1$.

$\triangle A 16-C L A D$

AGNIFICAIIJ

$150 \cap \%$.

$$
\begin{gathered}
\text { APEA } \\
41170 \% 21
\end{gathered}
$$

-0. VULAE(CC)

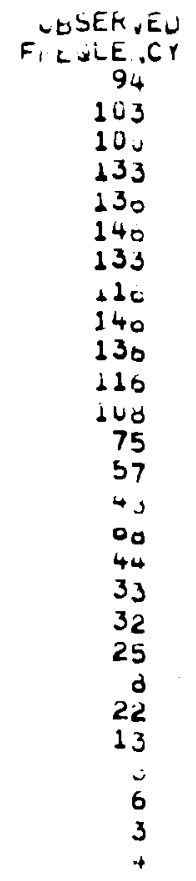
JENSITY ESTI AAT:
(PATICLES/CCA)
$4.6169+1$ ) $4.6169+11$
$5.1496+i 1$

$2.3886+11$

$6.4033+11$

$0.0504+11$

$7.5494+11$

$0.1+72+11$

$3.3210+11$

$6.7440+11$

$6.4121+11$

$5.0417+i 1$

$5.2926+11$
$3.0199+11$

$1.833 c+11$

$8.55-3+1$

$2,7069+1$ :

$1.4509+11$

$8.7053+10$

$9.9524+10$

$-1.2321+10$

$6.5718+11$

$0.5713+10$

$1.1320+25$

$1.4958+10$

$4.7489+i 9$

$1.2077+1$
STAIDAQU DEVIATIO. UF UE::SITY ESTIMATE $1.7393+11$ $1.6944+11$ $1.5993+11$ $1.6900+11$ $1.5047+11$
$1.5399+11$ $1.376+11$ i. $2342+11$ $1.2342+11$ $1.2668+11$

$1.1393+11$

$9.8961+10$

$3.8029+10$

$6.9120+10$

$3.6980+10$

$5.2641+1$ ?

$5.3612+10$

$4.0755+10$

$3.3530+10$

$3.7472+18$

$2.4570+16$

$2.4570+16$
$1.5105+10$

$1.0501+10$

$2.0501+11$

$1.4657+10$

$9.6795+09$

$0.100 u+09$
$6.3397+? 9$

SMOJTIED DENSITY

P ARTICIESTCCIMICRON

$6.5250+13$

$6.525 J+13$

$6.5250+13$

$.8658+13$

$8658+13$

$.8658+13$
$9.8658+13$

$5.805 \theta+13$

$5.8858+13$

$5.8858+13$

$5.8858+13$

$4.9992+13$

$4.9992+13$

$4 \cdot 9992+13$

$1.4014+13$

$1.4014+13$

$1.401++13$

$1.0151+13$

$1.0151+13$

$2.8649+12$

$2.8649+12$

$2.8649+12$
$2.3649+12$

.

$5666+12$

$.5666+12$

$1.5666+12$

$3.5683+11$

$3.5693+11$
$3.5683+11$

STANDARO CE, IATICN

OF SMOOTHED CENSITY

$1.2024+13$

$9.2637+12$

$9.2637+12$

$9.2637+12$

$6.1814+12$

$0.1814+12$

$0.1814+12$

$6.1814+12$

$3.9750+12$

$3.9750+12$

$3.9750+12$

$2.0276+12$

$2.0276+12$

$2.0276+12$

$1.2265+12$

$1.2265+12$

$1.2265+12$

$5.8162+11$

$5.8162+11$

$5.8162+11$

$3.0595+11$

$3.0595+11$

$3.0595+1$

$1.0607+1$

$1.0607+11$

$1.9607+11$ 


\begin{tabular}{|c|c|c|c|c|c|c|c|c|c|c|c|}
\hline & 1 & 2 & 3 & 4 & 5 & 6 & 7 & 8 & 9 & 10 & \\
\hline 1 & $\begin{array}{r}.00000 \\
.000 u \\
.0001: L\end{array}$ & $\begin{array}{r}.60000 \\
.00000 \\
.00000\end{array}$ & $\begin{array}{r}.00100 \\
.00000 \\
.00000\end{array}$ & $\begin{array}{l}.00000 \\
.00000 \\
.00000\end{array}$ & $\begin{array}{l}.00000 \\
.00000 \\
.00030\end{array}$ & $\begin{array}{r}.00000 \\
.00000 \\
.00000\end{array}$ & $\begin{array}{l}.00000 \\
.00000 \\
.0 n 00 n\end{array}$ & $\begin{array}{r}.00000 \\
.00000 \\
.00000\end{array}$ & $\begin{array}{r}.00000 \\
.00000\end{array}$ & $\begin{array}{l}.00000 \\
.00 n n ?\end{array}$ & \\
\hline 2 & $\begin{array}{r}.00046 \\
.00352 \\
. .00030\end{array}$ & $\begin{array}{r}1.00000 \\
-.00204 \\
-.00120\end{array}$ & $\begin{array}{r}-.28404 \\
-.00304 \\
.01214\end{array}$ & $\begin{array}{r}-.07484 \\
-.00219 \\
.00069\end{array}$ & $\begin{array}{r}-.04458 \\
. .00149 \\
-.00037\end{array}$ & $\begin{array}{r}-.02606 \\
-.00112 \\
-.00006\end{array}$ & $\begin{array}{r}-.02079 \\
-.00226 \\
-.00003\end{array}$ & $\begin{array}{r}-.01957 \\
.00073 \\
-.00006\end{array}$ & $\begin{array}{r}-.03360 \\
.00020\end{array}$ & $\begin{array}{l}.05518 \\
-.00009\end{array}$ & \\
\hline 3 & $\begin{array}{r}.00000 \\
.05147 \\
.000 .7\end{array}$ & $\begin{array}{r}-.28464 \\
.04316 \\
-.00429\end{array}$ & $\begin{aligned} 1.00000 \\
-.00236 \\
-.00064\end{aligned}$ & $\begin{array}{r}-.24832 \\
-.00224 \\
.00164\end{array}$ & $\begin{array}{r}-.09344 \\
-.00163 \\
.00008\end{array}$ & $\begin{array}{r}-.04282 \\
-.00095 \\
-.00008\end{array}$ & $\begin{array}{r}-.02774 \\
-.00183 \\
-.0060\end{array}$ & $\begin{array}{r}-.01896 \\
-.00177 \\
-.00006\end{array}$ & $\begin{array}{r}-.01608 \\
.00058\end{array}$ & $\begin{array}{r}-.03061 \\
.00 .21\end{array}$ & \\
\hline 4 & $\begin{array}{l}.00000 \\
-.028 \cup 2 \\
.00021\end{array}$ & $\begin{array}{r}-.07464 \\
.04648 \\
.00003\end{array}$ & $\begin{array}{r}-.24832 \\
.00266 \\
-.00016\end{array}$ & $\begin{array}{l}1.00000 \\
=.00173 \\
=.00041\end{array}$ & $\begin{array}{r}-.30795 \\
-.00170 \\
.00104\end{array}$ & $\begin{array}{r}-.09290 \\
-.00105 \\
.00006\end{array}$ & $\begin{array}{r}-.04699 \\
-.00195 \\
-.00004\end{array}$ & $\begin{array}{r}-.02591 \\
-.00141 \\
-.00007\end{array}$ & $\begin{array}{r}-.01494 \\
-.00155\end{array}$ & $\begin{array}{r}-.01736 \\
.00061\end{array}$ & \\
\hline 5 & $\begin{array}{l}.00000 \\
-.01523 \\
.00052\end{array}$ & $\begin{array}{r}-.04458 \\
-.02407 \\
.00409\end{array}$ & $\begin{array}{r}-.09344 \\
.04078 \\
-.00003\end{array}$ & $\begin{array}{r}-.30795 \\
.00215 \\
-.00015\end{array}$ & $\begin{array}{l}1.00000 \\
=.00109 \\
-.00043\end{array}$ & $\begin{array}{r}=.27432 \\
=.00093 \\
.00095\end{array}$ & $\begin{array}{r}-.09029 \\
-.00196 \\
.00105\end{array}$ & $\begin{array}{r}-.03947 \\
-.00227 \\
-.00008\end{array}$ & $\begin{array}{r}-.01826 \\
-.00098\end{array}$ & $\begin{array}{r}-.01676 \\
-.00132\end{array}$ & it \\
\hline 6 & $\begin{array}{l}.00000 \\
. .01595 \\
. .00110\end{array}$ & $\begin{array}{r}-.02606 \\
-.01277 \\
.00017\end{array}$ & $\begin{array}{r}-.04262 \\
-.01966 \\
.00017\end{array}$ & $\begin{array}{r}-.0 \times 240 \\
.03346 \\
-.00002\end{array}$ & $\begin{array}{r}-.27432 \\
-.00208 \\
-.00009\end{array}$ & $\begin{aligned} 1.00000 \\
-.00051 \\
-.00026\end{aligned}$ & $\begin{array}{r}-.28182 \\
=.00209 \\
.00062\end{array}$ & $\begin{array}{r}-.08457 \\
-.00141 \\
.00003\end{array}$ & $\begin{array}{r}-.03114 \\
-.00096\end{array}$ & $\begin{array}{r}-.02340 \\
-.00101\end{array}$ & \\
\hline 7 & $\begin{array}{l}.00000 \\
=.02271 \\
. .00112\end{array}$ & $\begin{array}{r}-.02079 \\
-.02397 \\
-.00077\end{array}$ & $\begin{array}{r}-.02774 \\
-.01243 \\
.00044\end{array}$ & $\begin{array}{r}-.04699 \\
-.01663 \\
.00012\end{array}$ & $\begin{array}{r}-.09029 \\
.02835 \\
-.00002\end{array}$ & $\begin{array}{r}-.29182 \\
.00217 \\
-.00012\end{array}$ & $\begin{array}{l}1.00000 \\
=.00168 \\
=.00037\end{array}$ & $\begin{array}{r}-.27163 \\
-.00150 \\
.00078\end{array}$ & $\begin{array}{r}-.06818 \\
-.00108\end{array}$ & $\begin{array}{r}-.03981 \\
-.00111\end{array}$ & \\
\hline 8 & $\begin{array}{l}.00000 \\
. .04160 \\
. .00119\end{array}$ & $\begin{array}{r}-.01957 \\
-.02163 \\
-.04012\end{array}$ & $\begin{array}{r}-.01896 \\
-.01556 \\
-.00108\end{array}$ & $\begin{array}{r}-.02591 \\
-.01109 \\
.00037\end{array}$ & $\begin{array}{r}-.03947 \\
-.01607 \\
.00010\end{array}$ & $\begin{array}{r}-.08457 \\
.02615 \\
.00000\end{array}$ & $\begin{array}{r}-.27163 \\
.00180 \\
-.00001\end{array}$ & $\begin{array}{l}1.00000 \\
=.00123 \\
-.00007\end{array}$ & $\begin{array}{r}-.24423 \\
-.00118\end{array}$ & $\begin{array}{r}-.09107 \\
-.00129\end{array}$ & \\
\hline 9 & $\begin{array}{l}.00000 \\
-.094+5 \\
-.001+.\end{array}$ & $\begin{array}{r}-.03364 \\
-.03974 \\
.0461\end{array}$ & $\begin{array}{r}-.01608 \\
-.02445 \\
-.00098\end{array}$ & $\begin{array}{r}-.01494 \\
-.01406 \\
-.00086\end{array}$ & $\begin{array}{r}-.01826 \\
-.01196 \\
.00024\end{array}$ & $\begin{array}{r}-.03114 \\
-.02094 \\
.02010\end{array}$ & $\begin{array}{r}-.06812 \\
.03423 \\
.00001\end{array}$ & $\begin{array}{r}-.24423 \\
.00168 \\
-.00005\end{array}$ & $\begin{array}{l}1.00000 \\
=.00092\end{array}$ & $\begin{array}{r}-.31203 \\
-.00145\end{array}$ & \\
\hline iv & $\begin{array}{l}.00000 \\
. .27942 \\
-.00139\end{array}$ & $\begin{array}{r}.551 d \\
-.07 d 3 t \\
.06005\end{array}$ & $\begin{array}{r}-.03061 \\
-.03808 \\
-.00200\end{array}$ & $\begin{array}{r}-.0173 t \\
-.01770 \\
-.00073\end{array}$ & $\begin{array}{r}-.01676 \\
-.01015 \\
-.00056\end{array}$ & $\begin{array}{r}-.02340 \\
-.00756 \\
.00024\end{array}$ & $\begin{array}{r}-.03981 \\
-.01+74 \\
.00006\end{array}$ & $\begin{array}{r}-.09107 \\
.02498 \\
-.00001\end{array}$ & $\begin{array}{r}-.31203 \\
.00146\end{array}$ & $\begin{array}{l}1.00000 \\
\quad .00207\end{array}$ & $\sum_{i}^{\varpi}$ \\
\hline 11 & $\begin{array}{l}.00000 \\
1.00605 \\
-.002 .2\end{array}$ & $\begin{array}{r}.0353 \\
-.26610 \\
.64015 \\
\end{array}$ & $\begin{array}{r}.05147 \\
-.08480 \\
-. .119 \\
\end{array}$ & $\begin{array}{r}-.02842 \\
=.03179 \\
-.20083\end{array}$ & $\begin{array}{r}-.01523 \\
-.11497 \\
-.0040\end{array}$ & $\begin{array}{r}-.01595 \\
-.00768 \\
-.00756\end{array}$ & $\begin{array}{r}-.02271 \\
-.01031 \\
.03015\end{array}$ & $\begin{array}{r}-.34160 \\
-.01327 \\
.00007\end{array}$ & $\begin{array}{r}-.09445 \\
.02217\end{array}$ & $\begin{array}{r}-.27992 \\
.00128\end{array}$ & $\tilde{0}$ \\
\hline
\end{tabular}




\begin{tabular}{|c|c|c|c|c|c|c|c|c|c|c|c|}
\hline 12 & $\begin{array}{l}.00000 \\
. .26610 \\
.00106\end{array}$ & 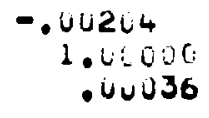 & $\begin{array}{r}.00316 \\
-.29207 \\
-.04141\end{array}$ & $\begin{array}{r}.04688 \\
-.07394 \\
.000103\end{array}$ & $\begin{array}{r}-.02407 \\
-.02816 \\
-.00047\end{array}$ & $\begin{array}{r}-.01277 \\
-.01199 \\
-.00056\end{array}$ & $\begin{array}{r}-.21397 \\
-.01350 \\
-.03046\end{array}$ & $\begin{array}{r}-.2163 \\
-.00947 \\
.00024\end{array}$ & $\begin{array}{r}-.03974 \\
-.01423\end{array}$ & $\begin{array}{r}-.07836 \\
.02395\end{array}$ & \\
\hline & $\begin{array}{r}.00000 \\
.0048 \mathrm{U} \\
.023 u 2\end{array}$ & $\begin{array}{r}-.00304 \\
-.29207 \\
.00155\end{array}$ & $\begin{array}{r}-.00236 \\
1.00000 \\
-.00125\end{array}$ & $\begin{array}{r}.00266 \\
-.25115 \\
-.00118\end{array}$ & $\begin{array}{r}.04078 \\
-.06456 \\
-.00553\end{array}$ & $\begin{array}{r}-.01966 \\
-.02228 \\
-.00061\end{array}$ & $\begin{array}{r}-.01243 \\
-.02102 \\
-.00026\end{array}$ & $\begin{array}{r}-.01556 \\
-.01099 \\
-.00048\end{array}$ & $\begin{array}{r}-.02445 \\
-.00809\end{array}$ & $\begin{array}{r}-.03809 \\
-.01312\end{array}$ & \\
\hline & $\begin{array}{l}.000 u 0 \\
-.0317 y \\
.00951\end{array}$ & $\begin{aligned}-.0 \cup 219 \\
-.673>4 \\
.013<4\end{aligned}$ & $\begin{array}{r}-.01224 \\
-.25115 \\
.01124\end{array}$ & $\begin{array}{r}-.04173 \\
1.00000 \\
-.00121\end{array}$ & $\begin{array}{l}.0 U 215 \\
-.25258 \\
-.00069\end{array}$ & $\begin{array}{r}.03346 \\
-.05996 \\
-.00085\end{array}$ & $\begin{array}{r}-.01663 \\
-.04324 \\
-.00036\end{array}$ & $\begin{array}{r}. .01109 \\
-.01878 \\
-.00068\end{array}$ & $\begin{array}{r}-.01406 \\
-.00991\end{array}$ & $\begin{aligned} &-. .177 \pi \\
&-.017228\end{aligned}$ & \\
\hline & $\begin{array}{l}.04000 \\
.01457 \\
-.01225\end{array}$ & $\begin{aligned}-.04+4 \\
-.52010 \\
-.01>22\end{aligned}$ & $\begin{array}{r}-.00163 \\
-.06456 \\
.02853\end{array}$ & $\begin{array}{r}-.00170 \\
-.25256 \\
.06104\end{array}$ & $\begin{array}{l}-.01109 \\
1.00000 \\
-.00060\end{array}$ & $\begin{array}{l}.00209 \\
-.23528 \\
-.06106\end{array}$ & $\begin{array}{l}.02835 \\
-.10548 \\
-.00047\end{array}$ & $\begin{array}{r}-.01607 \\
-.03790 \\
-.00091\end{array}$ & $\begin{array}{r}-.01196 \\
-.01764\end{array}$ & $\begin{array}{r}-.01015 \\
-.01335\end{array}$ & \\
\hline 10 & $\begin{array}{l}.00400 \\
-.00760 \\
.01362\end{array}$ & $\begin{array}{l}-.0 .11 \% \\
-.01198 \\
-.00439\end{array}$ & $\begin{array}{r}-.0 u i 95 \\
-.02220 \\
-.01366\end{array}$ & $\begin{array}{r}-.0105 \\
-.05996 \\
.02340\end{array}$ & $\begin{array}{r}-.00053 \\
-.23528 \\
.00102\end{array}$ & $\begin{array}{r}-.00051 \\
1.00000 \\
-.00095\end{array}$ & $\begin{array}{r}.00217 \\
-.35315 \\
-.00054\end{array}$ & $\begin{array}{r}.02615 \\
-.08568 \\
. .00111\end{array}$ & $\begin{array}{r}-.02084 \\
-.03196\end{array}$ & $\begin{array}{r}-.00756 \\
-.01992\end{array}$ & \\
\hline 17 & $\begin{array}{l}.00000 \\
-.01051 \\
.01745\end{array}$ & $\begin{array}{r}-.04226 \\
-.01358 \\
-.04168\end{array}$ & $\begin{array}{r}-.00183 \\
-.02102 \\
-.04790\end{array}$ & $\begin{array}{r}-.00195 \\
-.04324 \\
-.0 \cup 835\end{array}$ & $\begin{array}{r}-.00196 \\
-.105+9 \\
.11353\end{array}$ & $\begin{array}{r}-.00209 \\
-.35315 \\
.00368\end{array}$ & $\begin{array}{l}-.00168 \\
1.00000 \\
-.00035\end{array}$ & $\begin{array}{l}.00190 \\
-.24410 \\
-.00110\end{array}$ & $\begin{array}{l}.03423 \\
-.06157\end{array}$ & $\begin{array}{c}-.01474 \\
-.07743 \\
.\end{array}$ & \\
\hline & $\begin{array}{r}.00000 \\
=.01327 \\
=.03729\end{array}$ & $\begin{array}{l}.00073 \\
-.00947 \\
-.00299\end{array}$ & $\begin{array}{r}-.00177 \\
-.02093 \\
-.01278\end{array}$ & $\begin{array}{r}-.00141 \\
-.01878 \\
-.00843\end{array}$ & $\begin{array}{r}-.11127 \\
-.03790 \\
-.01016\end{array}$ & $\begin{array}{r}-.30141 \\
-.08568 \\
.01727\end{array}$ & $\begin{array}{r}-.00150 \\
-.24410 \\
.00079\end{array}$ & $\begin{array}{r}-.00123 \\
1.00000 \\
-.00124\end{array}$ & $\begin{array}{l}.00168 \\
-.24900\end{array}$ & $\begin{array}{l}.0249 A \\
=.08964\end{array}$ & $\dot{\infty}$ \\
\hline 10 & $\begin{array}{r}.00000 \\
.02217 \\
-.08979\end{array}$ & $\begin{array}{l}.00020 \\
=.01423 \\
-.00706\end{array}$ & $\begin{array}{l}.00058 \\
=.00809 \\
=.02184\end{array}$ & $\begin{array}{r}-.00155 \\
-.00961 \\
-.01150\end{array}$ & $\begin{array}{r}-.0 \cup 098 \\
-.01764 \\
-.00552\end{array}$ & $\begin{array}{r}-.00096 \\
-.03196 \\
-.00829\end{array}$ & $\begin{array}{r}-.00108 \\
-.06157 \\
.01305\end{array}$ & $\begin{array}{r}-.0011_{B} \\
-.24900 \\
.00041\end{array}$ & $\begin{array}{r}-.00092 \\
1.00000\end{array}$ & $\begin{array}{l}.0146 \\
-.29411\end{array}$ & \\
\hline & $\begin{array}{r}.00000 \\
.00126 \\
-.28976\end{array}$ & $\begin{array}{r}-.00009 \\
.02385 \\
-.02120\end{array}$ & $\begin{array}{l}.00021 \\
=.01312 \\
=.03926\end{array}$ & $\begin{array}{l}.00601 \\
-.00828 \\
-.01807\end{array}$ & $\begin{array}{r}-.132 \\
-.11335 \\
-.16700\end{array}$ & $\begin{array}{r}-.00101 \\
-.01992 \\
-.00717\end{array}$ & $\begin{array}{r}-.00111 \\
-.03043 \\
-.01005\end{array}$ & $\begin{array}{r}-.0120 \\
-.08064 \\
.01719\end{array}$ & $\begin{array}{r}-.00145 \\
-.29411\end{array}$ & $\begin{aligned}-.00107 \\
1.00000\end{aligned}$ & \\
\hline$c 1$ & $\begin{array}{l}.0 \text { Uuvo } \\
-.001<3 \\
1.06060\end{array}$ & $\begin{array}{r}-.0403 c \\
.00106 \\
. .10712\end{array}$ & $\begin{array}{r}-.00017 \\
.02302 \\
-.05672\end{array}$ & $\begin{array}{l}.00021 \\
-.00951 \\
-.03597\end{array}$ & $\begin{array}{l}.0 .052 \\
=.01225 \\
=.01123\end{array}$ & $\begin{array}{r}-. \operatorname{co11} \\
-.01362 \\
-.00374\end{array}$ & $\begin{array}{r}-.00111 \\
-.01745 \\
-.00312\end{array}$ & $\begin{array}{r}-.00119 \\
-.03729 \\
-.00458\end{array}$ & $\begin{array}{r}-.00140 \\
-.08979\end{array}$ & $\begin{array}{r}-.00139 \\
-.28976\end{array}$ & \\
\hline$C<$ & $\begin{array}{r}.0400 u \\
.00013 \\
-.10712\end{array}$ & $\begin{array}{r}-.041<0 \\
.04036 \\
1.00000\end{array}$ & $\begin{array}{r}-.00019 \\
.00155 \\
-.46461\end{array}$ & $\begin{array}{r}.000 \cup 3 \\
.01324 \\
. .11638\end{array}$ & $\begin{array}{r}. \because J \cup \cup 9 \\
-.01922 \\
-.03070\end{array}$ & $\begin{array}{l}.00017 \\
-.00439 \\
-.02785\end{array}$ & $\begin{array}{r}-.00077 \\
-.00168 \\
-.00703\end{array}$ & $\begin{array}{r}-.01012 \\
-.00299 \\
-.00955\end{array}$ & $\begin{array}{l}.00001 \\
-.00706\end{array}$ & $\begin{array}{l}.00005 \\
-.0212 n\end{array}$ & \\
\hline 3 & $\begin{array}{l}\text {-0uvuu } \\
-. \text {. } 119 \\
-.0907 \mathrm{C}\end{array}$ & $\begin{array}{l}.01214 \\
=.0 i 1+1 \\
-.464 t 1\end{array}$ & $\begin{array}{r}-.00064 \\
-.00125 \\
1.00000\end{array}$ & $\begin{array}{r}-.00016 \\
.00124 \\
-.25176\end{array}$ & $\begin{array}{r}-.00003 \\
.02858 \\
-.04650\end{array}$ & $\begin{array}{l}.00017 \\
.001366 \\
-.02525\end{array}$ & $\begin{array}{l}.00044 \\
-.00790 \\
-.00775\end{array}$ & $\begin{array}{r}-.00109 \\
-.01278 \\
-.00948\end{array}$ & $\begin{array}{l}-.00098 \\
-.02134\end{array}$ & $\begin{array}{r}-.00100 \\
-.03926\end{array}$ & $\begin{array}{l}E^{1} \\
0 \\
0\end{array}$ \\
\hline
\end{tabular}




\begin{tabular}{|c|c|c|c|c|c|c|c|c|c|c|}
\hline$<$ & $\begin{array}{l}\text { - Uului } \\
-.00023 \\
-.03541\end{array}$ & 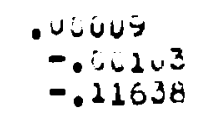 & $\begin{array}{l}.64260 \\
=.00118 \\
-.25176\end{array}$ & $\begin{array}{r}-.06041 \\
-.00121 \\
2.00000\end{array}$ & $\begin{array}{r}-.015 \\
.001 .7 \\
-.19975\end{array}$ & $\begin{array}{r}-.00002 \\
.02340 \\
-.07044\end{array}$ & $\begin{array}{l}.00012 \\
-.00835 \\
-.01831\end{array}$ & $\begin{array}{l}.00037 \\
-.00843 \\
.001913\end{array}$ & $\begin{array}{r}-.00086 \\
-.01150\end{array}$ & $\begin{aligned}-.00073 \\
-.01907\end{aligned}$ \\
\hline 25 & $\begin{array}{l}.0 \text { UUUu } \\
. .00040 \\
.001123\end{array}$ & $\begin{array}{r}-.0007 \\
-.00047 \\
-.03070\end{array}$ & $\begin{array}{l}.00008 \\
-.00053 \\
.004650\end{array}$ & $\begin{array}{l}.00104 \\
-.00069 \\
-.19975\end{array}$ & $\begin{array}{l}-.0043 \\
-000060 \\
1.00000\end{array}$ & $\begin{array}{r}-.00009 \\
.00102 \\
-.31473\end{array}$ & $\begin{array}{r}-.00002 \\
.01353 \\
-.05744\end{array}$ & $\begin{array}{l}.00010 \\
-.01016 \\
. .04660\end{array}$ & $\begin{array}{l}.00024 \\
-.00552\end{array}$ & $\begin{array}{r}-.00056 \\
-.0070 .0\end{array}$ \\
\hline$\angle O$ & $\begin{array}{l}.000 \cup 0 \\
-.00056 \\
-.00274\end{array}$ & $\begin{array}{r}-.00006 \\
-.00 .056 \\
-.02045\end{array}$ & $\begin{array}{r}-. \text { ouvue } \\
-.0 .061 \\
-.02525\end{array}$ & $\begin{array}{l}.00006 \\
-.00085 \\
-.07044\end{array}$ & $\begin{array}{l}.00095 \\
-.04106 \\
-.31473\end{array}$ & $\begin{array}{r}-.00026 \\
-.00095 \\
1.00000\end{array}$ & $\begin{array}{r}-.00012 \\
.00068 \\
-.19716\end{array}$ & $\begin{array}{r}.00000 \\
.01727 \\
.009936\end{array}$ & $\begin{array}{l}.00010 \\
-.00828\end{array}$ & $\begin{array}{l}.00024 \\
-.00717\end{array}$ \\
\hline$<7$ & $\begin{array}{r}.00000 \\
.00025 \\
-.00312\end{array}$ & $\begin{array}{r}-.00003 \\
-.00046 \\
-.00703\end{array}$ & $\begin{array}{r}-.00003 \\
-.06026 \\
-.00775\end{array}$ & $\begin{array}{r}-.00004 \\
-.00036 \\
-.01830\end{array}$ & $\begin{array}{l}.00005 \\
-.00047 \\
-.05744\end{array}$ & $\begin{array}{l}.00062 \\
-.00054 \\
-.19716\end{array}$ & $\begin{array}{r}-.00037 \\
-.00035 \\
1.00000\end{array}$ & $\begin{array}{r}-.00001 \\
.00079 \\
-.40324\end{array}$ & $\begin{array}{r}.00001 \\
.01305\end{array}$ & $\begin{array}{l}.00005 \\
-.01005\end{array}$ \\
\hline$\angle 0$ & $\begin{array}{r}.04000 \\
.00007 \\
-.0 J 458\end{array}$ & $\begin{array}{r}-.00006 \\
.00024 \\
-.00955\end{array}$ & $\begin{array}{r}-.0005 \\
-.00048 \\
-.00548\end{array}$ & $\begin{array}{r}-.00007 \\
-.00068 \\
-.02913\end{array}$ & $\begin{array}{r}-. J 048 \\
-.00091 \\
-.04660\end{array}$ & $\begin{array}{l}.00003 \\
-.00111 \\
-.09936\end{array}$ & $\begin{array}{l}.00070 \\
-.00117 \\
-.40324\end{array}$ & $\begin{aligned}-.00 C C 7 \\
-.00124 \\
1.00000\end{aligned}$ & $\begin{array}{r}-.00005 \\
.30041\end{array}$ & $\begin{array}{r}-.00 .911 \\
.01719\end{array}$ \\
\hline
\end{tabular}



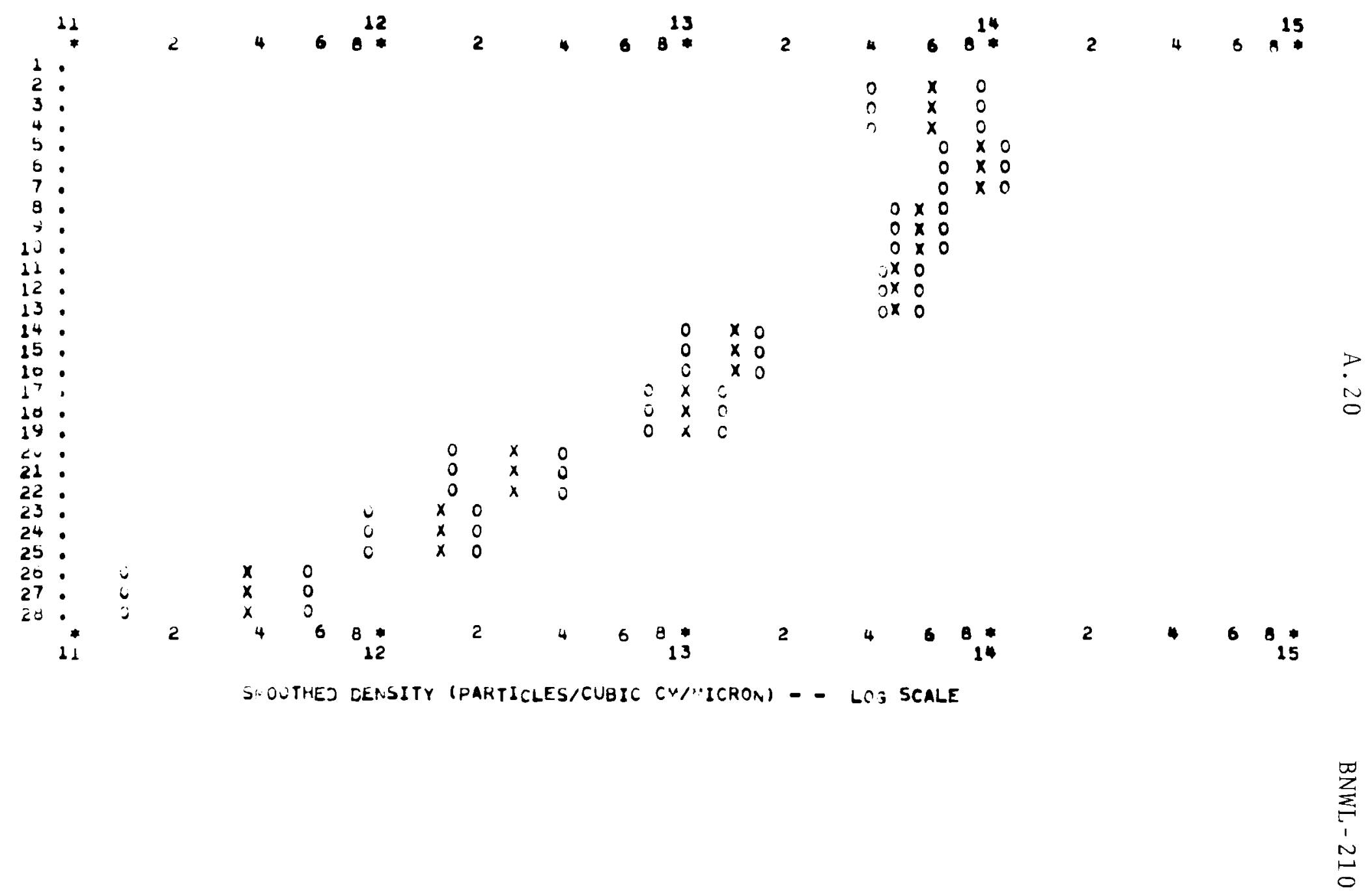
BNWL - 210

\section{DISTRIBUTION}

No. of Copies

1

Atomic Energy Commission, Richland

Office of DRDT Site Representative

J. H. Sako

4

1 Atomic Energy of Canada, Ltd.

Atomic Energy Commission, Washington

R. E. Cunningham

L. E. Steele

D. K. Stevens

J. M. Simmons

Chalk River Nuclear Laboratories

Reactor Materials Branch

Chalk River, Ontario, Canada

A. M. Ross

Argonne Cancer Research Hospita1

Armed Forces Radiobiology Research Institute

Atomics International

C. E. Weber

$1 \quad$ Carnegie Institute of Technology

1 Central Electricity Generating Board

Berkeley Nuclear Laboratory

Berkeley, Gloucestershire, England

$\mathrm{J}$. Harris

$1 \quad$ Columbia University (Havens)

$1 \quad$ Columbia University (NYO-187)

1 Commissairat a 1 ' Energie Atomique

Centre d' Etudes de Saclay

Voite Postale No. 2

Gif-sur-Yvette

(Seine-et-Oise), France

J. Lehmann 
No. of Copies

3

Douglas United Nuclear

T. W. Ambrose

Le Roi H. Rice

J. T. Stringer

2

General Electric Company, Richland.

T. W. Evans

Milton Lewis

1 Knolls Atomic Power Laboratory

C. H. Randa11

1 Lockheed-Georgia, Co.,

Marietta, Georgia

E. E. Underwood

$1 \quad$ National Bureau of Standards

G. A. Moore

1 National Institutes of Health

2 Naval Radiological Defense Laboratory

$1 \quad$ New York University

1 Princeton University (Sherr)

4 Richland Operations Office

C. R. Qualheim

R. K. Sharp

Technical Information Library

1 University of California, Livermore

James Hadley

1 University of California, Los Angeles

1 University of Florida

R. T. DeHoff 
No. of

Copies

1

1

1

1

1

77

University of Michigan

M. J. Sinnott

University of Rochester

University of Rochester (Kaplon)

University of Washington (Geballe)

Yale University (Breit)

Battelle-Northwest

R. P. A1len

A. L. Bement

C. A. Bennett

T. K. Bierlein

J. J. Cadwe 11

W. J. Clark

T. T. Claudson

D. R. deHalas

J. J. Fuquay

C. R. Hann

L. A. Hartcorn

B. Hayward

J. J. Holmes

J. L. Jaecke

R. S. Kemper

G. A. Last

R. D. Leggett (7)

I. S. Levy

B. Maste 1

K. R. Merckx: (15)

J. E. Minor

W. L. Nicholson (16)

R. E. Nightingale

D. P. O'Keefe

W. E. Roake

R. K. Robinson

C. L. Simpson

F. A. Smidt, Jr.

R. W. Stewart

J. B. Vetrano

J.W. Weber

R. G. Wheeler 


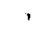

, 